\title{
A systematic review of the application of Machine Learning in the detection and classification of transposable elements
}

\author{
Simon Orozco-Arias ${ }^{\text {Corresp., } 1,2}{ }^{2}$, Gustavo Isaza ${ }^{2}$, Romain Guyot $^{3,4}$, Reinel Tabares-Soto ${ }^{4}$ \\ 1 Department of Computer Science, Universidad Autónoma de Manizales, Manizales, Caldas, Colombia \\ 2 Department of Systems and informatics, Universidad de Caldas, Manizales, Caldas, Colombia \\ 3 Institut de Recherche pour le Développement, CIRAD, Univ. Montpellier, France, Montpellier, France \\ 4 Department of Electronics and Automation, Universidad Autónoma de Manizales, Manizales, Caldas, Colombia \\ Corresponding Author: Simon Orozco-Arias \\ Email address: simon.orozco.arias@gmail.com
}

Background. Transposable elements (TEs) constitute the most common repeated sequences in eukaryotic genomes. Recent studies demonstrated their deep impact on species diversity, adaptation to the environment, and diseases. Although there are many conventional bioinformatics algorithms for detecting and classifying TEs, none have achieved reliable results on different types of TEs. Machine learning (ML) techniques can automatically extract hidden patterns and novel information from labeled or non-labeled data and have been applied to solving several scientific problems.

Methodology. We followed the Systematic Literature Review process, applying the six stages of the review protocol from it, but added a previous stage, which aims to detect the need for a review. Then search equations were formulated and executed in several literature databases. Relevant publications were scanned and used to extract evidence to answer research questions.

Results. Several ML approaches have already been tested on other bioinformatics problems with promising results, yet there are few algorithms and architectures available in literature focused specifically on TEs, despite representing the majority of the nuclear DNA of many organisms. Only 35 papers were found and categorized as relevant in TE or related fields.

Conclusions. ML is a powerful tool that can be used to address many problems. Although ML techniques have been used widely in other biological tasks, their utilization in TE analyses is still limited. Following the Systematic Literature Review process, it was possible to notice that the use of ML for TE analyses (detection and classification) is an open problem, and this new field of research is growing in interest. 
1 A systematic review of the application of Machine Learning in the detection and

2 classification of transposable elements

3 Simon Orozco-Arias ${ }^{1,2}$, Gustavo Isaza ${ }^{2}$, Romain Guyot ${ }^{3,4}$, Reinel Tabares-Soto ${ }^{3}$

$4{ }^{1}$ Department of Computer Science, Universidad Autónoma de Manizales, Manizales,

5 Colombia

62 Department of Systems and Informatics, Universidad de Caldas, Manizales, Colombia

$7{ }^{3}$ Department of Electronics and Automation, Universidad Autónoma de Manizales,

8 Manizales, Colombia

$9 \quad 4$ Institut de Recherche pour le Développement, CIRAD, Univ. Montpellier, France

10 Corresponding Author:

11 Simon Orozco-Arias ${ }^{1,2}$

12 Calle 65 No. 26-10, Manizales, Caldas, 170002, Colombia.

13 Email address: simon.orozco.arias@gmail.com

\section{Abstract}

Background. Transposable elements (TEs) constitute the most common repeated sequences in eukaryotic genomes. Recent studies demonstrated their deep impact on species diversity, adaptation to the environment, and diseases. Although there are many conventional bioinformatics algorithms for detecting and classifying TEs, none have achieved reliable results on different types of TEs. Machine learning (ML) techniques can automatically extract hidden patterns and novel information from labeled or non-labeled data and have been applied to solving several scientific problems.

Methodology. We followed the Systematic Literature Review process, applying the six stages of the review protocol from it, but added a previous stage, which aims to detect the need for a review. Then search equations were formulated and executed in several literature databases. Relevant publications were scanned and used to extract evidence to answer research questions.

Results. Several ML approaches have already been tested on other bioinformatics problems with promising results, yet there are few algorithms and architectures available in literature focused specifically on TEs, despite representing the majority of the nuclear DNA of many organisms. Only 35 papers were found and categorized as relevant in TE or related fields.

Conclusions. ML is a powerful tool that can be used to address many problems. Although ML techniques have been used widely in other biological tasks, their utilization in TE analyses is still limited. Following the Systematic Literature Review process, it 
was possible to notice that the use of ML for TE analyses (detection and classification) is an open problem, and this new field of research is growing in interest.

Keywords: transposable elements, retrotransposons, detection, classification, bioinformatics, machine learning, deep learning

\section{Introduction}

Transposable elements (TEs) are genomic units with the ability to move from one locus to another within the genome. TEs have been found in all organisms and comprise the majority of the nuclear DNA content of plant genomes (Orozco-arias et al., 2018), such as in wheat, barley, and maize. In these species, up to $85 \%$ of the sequenced DNA is classified into repeated sequences (Choulet et al., 2014), of which TEs represent the most abundant and functionally relevant type (Ventola et al., 2017). Due to the high diversity of TE structures and transposition mechanisms, there are still numerous classification problems and debates on the classification systems (Piégu et al., 2015). TEs in eukaryotes are traditionally classified based on if the reverse transcription is needed for transposition (Class I or retrotransposons) or not (Class II or DNA transposons) (Schietgat et al., 2018). Retrotransposons can be further subclassified into four orders according to structural features and the life cycle of the element.

In plants, Long Terminal Repeat retrotransposon (LTR-RT) is the most frequent order (Gao et al., 2012; Grandbastien, 2015) and can contribute up to $80 \%$ of the plant genome size (e.g. in wheat, barley or the rubber tree) (Rahman et al., 2013). However, in humans, the non-LTR-RT order is the most common and is related to diseases such as cancer (Tang et al., 2017). Other levels of classification of TEs include sub-classes (only for DNA transposons which are distinguished by the number of DNA strands that are cut during transposition (Wicker et al., 2007)), superfamilies, lineages, and families (de Castro Nunes et al., 2018; Neumann et al., 2019).

Although several methods have been developed to detect TEs in genomes, including de novo, structure-based, comparative genomic, and homology-based (reviewed in (Orozco-Arias, Isaza \& Guyot, 2019)), there is no single bioinformatics tool achieving reliable results on different types of TEs (Loureiro et al., 2013b). Most of the algorithms available currently use a homology-based approach (Nakano et al., 2018b), but this method can present limited potential due to the vast diversity at the nucleotide level of TEs. Also, the repetitive nature of TEs, as well as their structural polymorphism, species specificity, and high divergence rate even among close relative species (Mustafin \& Khusnutdinova, 2018), represent significant obstacles and challenges for their analysis (Ou, Chen \& Jiang, 2018). Despite of the complexity, a well-curated detection and classification of TEs is important, due to these elements have key roles into genomes, such as in the chromosomal structure, their interaction with genes, and adaptation and evolution processes (Orozco-Arias, Isaza \& Guyot, 2019) and their annotation could provide insights into genomic dynamics (Wheeler et al., 2012). 
In recent years, machine learning $(\mathrm{ML})$ has been used by life scientists as a system for knowledge discovery (Ma, Zhang \& Wang, 2014), achieving promising results. ML can be defined as the process of designing a model that will be calibrated from the training information and a loss function through an optimization algorithm (Mjolsness \& DeCoste, 2001). Based on these extracted patterns, algorithms can then predict results from unknown data. Main ML training methods can be classified into supervised learning and unsupervised learning (Ceballos et al., 2019). The goal of supervised learning is to predict a discrete (classification) or continuous (regression) value for each data point by using a provided set of labeled training examples. In unsupervised learning, which is based on clustering algorithms, the goal is to self-learn inherent patterns within the data (Zou et al., 2018). The main objective of ML tasks is to optimize a cost function in terms of a set of parameters for a proposed model. In the optimization process, the proposed model is calibrated. With this aim, the data are randomly split into a minimum of three subsets (named hold-out method): training, validation, and test sets leaving the first set for learning patterns and hyper-parameters, the second set for choosing the best models, and the last set for obtaining more realistic accuracy. On the other hand, k-fold cross-validation randomly splits data into k-folds and then applies hold-out to each subset. (Zou et al., 2018). This process is crucial to avoid overfitting (also called overtraining) or underfitting (undertraining), which both lead to poor predictive performances. Therefore, the algorithm must reach an appropriate balance between model flexibility and the amount of training data. An overly simple model will underfit and fail to let the data 'speak', while an overly flexible model will overfit to spurious patterns in the training data and fail to generalize (Zou et al., 2018).

The design and implementation of a ML system is a complex process that can be done in three steps: 1) raw data preprocessing (i.e. features selection and extraction, data imputation, etc.), 2) learning or training of the model by using an appropriate $\mathrm{ML}$ algorithm or architecture (to calibrate the model), and 3) model evaluation through metrics (Ma, Zhang \& Wang, 2014). In some cases, the preprocessing step is very complex and relies on complicated algorithms to automate this task or on experts in the field. The use of deep learning (DL) in ML addresses the issue of selecting the correct data representation or the best features (Eraslan et al., 2019), avoiding the need for an expert in the area. DL has evolved as a sub-discipline of ML through the development of deep artificial neural networks (DNN) (i.e. neural networks with many hidden layers), such as auto-encoders, fully connected neural networks (FNN), convolutional neural networks (CNNs), recurrent neural networks (RNNs), among others (Eraslan et al., 2019). DL has shown successful results in life sciences (Yu, Yu \& Pan, 2017), especially in genomics. In this area, it has been used for identifying di $\square$ erent types of genomic elements, such as exons, introns, promoters, enhancers, positioned nucleosomes, splice sites, untranslated regions (UTR), etc. (Yue \& Wang, 2018).

Here, we performed a systematic review of applications of ML algorithms and architectures in TE detection and classification problems. We also discuss other uses of 
$115 \mathrm{ML}$ and $\mathrm{DL}$ in similar tasks that can be extrapolated to TE issues. To our knowledge,

116 this is the first review focused mainly on the use of MLin TEs.

\section{Survey Methodology}

118 Simon Orozco-Arias conducted an exhaustive literature review by applying the

119 Systematic Literature Review (SLR) process proposed by (Kitchenham \& Charters,

120 2007) and preferred reporting items for systematic reviews and meta-analyses

121 guidelines (Moher et al., 2009) (Figure 1). We followed the six stages of the review

122 protocol used in (Wen et al., 2012) but added a previous stage, which aims to detect the need for a review (Figure 2). First, we searched for other reviews to formulate questions related to the aim of this review, and then we selected the search strategy based on key terms and available databases. In the next step, we defined the exclusion criteria for filtering relevant articles that could contribute to answering the questions from the first stage. For this, we applied several filters in the Quality Assessment Checklist (fourth stage) to choose articles to be included in the following steps. Finally, we performed data extraction and data synthesis to process the information retrieved.

\section{Identification of the need for a review}

The strategy used was based on the guidelines proposed by (Wen et al., 2012) and used in (Franco-Bedoya et al., 2017) and (Tabares-Soto, Ramos-Pollan \& Isaza, 2019). To define the need for a systematic review, we searched through published and available reviews (secondary studies) on the topic of interest. We used equation 1 to search in the literature databases referenced in Table 1.

\section{("transposable element" OR retrotransposon OR transposon) AND ("machine} learning" OR "deep learning") AND (review OR "systematic review" OR overview $O R$ "state of the art" OR "systematic mapping")

The keywords were selected based on the following: i) type of information that we aimed to retrieve (TEs as well as retrotransposons and transposons classes), ii) techniques addressed in this review (machine learning and deep learning), and iii) keywords related to secondary studies.

All of the databases showed results using the search equation (106 results after filtering), yet only one secondary study (Dashti \& Masoudi-Nejad, 2010) specifically applied ML in TEs. However, this review published in 2010 focused only on support vector machine (SVM). Given the lack of secondary studies about this topic, we concluded that a systematic review of ML applications in TEs was needed.

\section{Research Questions}

The main aim of this review is to summarize and clarify trends, metrics, benefits, and possible ML techniques and architectures that have not yet been addressed in the detection and classification (for a graphical representation of the TEs classification, see figure 3 ) of TEs. With this in mind, we formulated the following questions: 
1. Q1. Are $M L$ approaches for TE analyses advantageous compared to bioinformatics approaches? It is important to identify if the application of novel tools like machine learning can contribute to improving current bioinformatics software. This is relevant since it is well-know that current methodologies are still far from yielding confident results in the detection and classification of TEs given their high variability and complexity (Bousios et al., 2012). On the other hand, many papers propose that TEs are involved in key characteristics of genomes, such as chromosome structure, environmental adaptation, and interspecific variability, among others. Therefore, the objective of Q1 is to determine how TEs detection and classification can be improved using ML to understand the dynamics and impacts of these elements better.

2. Q2. Which ML techniques are currently used to detect and classify TEs or other genomic data?

We were interested in knowing which algorithms or architectures have been tested on TEs or other genomic data, such as long non-coding regions or retrovirus.

3. Q3. What are the best parameters and most used metrics in algorithms and architectures to detect and classify TEs?

To avoid overfitting, it is important to use a splitting method to reduce dependence on the training data and to determine which type of data is better to use. Thus, we were interested in knowing which current papers addressed this step. Additionally, to compare algorithms and architectures, it is important to define metrics that accurately measure performance. It is also essential to assess if these techniques improve results compared to traditional bioinformatics software.

4. Q4. What are the most used DNA coding schemes in ML tasks?

Because TEs comprise categorical data (nucleotides), there are many ways to transform this information into numerical data required by $\mathrm{ML}$ algorithms. Therefore, we were interested in understanding how this transformation can contribute to improving results and which coding schemes are widely used in this kind of problem.

\section{Search design and study selection}

Once we identified the need for a review and formulated the research questions, we developed the search strategy to find research articles, chapter books, conference proceedings, and other review papers in the databases shown in Table 1. Similar to search equation 1 , we used general keywords related to a) type of genomic data and b) techniques used. We did not use specific keywords (such as specific algorithms or architectures) and any time limitations, because few relevant results were found on this topic. Major keywords were separated by the "AND" operator, and related keywords were linked using the Boolean operator "OR", as shown in equation 2: 
193 ("transposable element" OR retrotransposon OR transposon) AND ("machine 194 learning" OR "deep learning")

195 The literature search using equation 2 retrieved 403 candidate articles of which were

196 eliminated those that were: a) repeated (the same study was found in different

197 databases); b) of different types (books, posters, short articles, letters, and abstracts); c)

198 written in other languages (languages other than English). Then, we performed a fast

199 read process (i.e. title, abstract, and conclusion) to detect papers that could contribute

200 to answering the research questions. For this, we established the following inclusion

201 and exclusion criteria.

202 Inclusion criteria

203

204

205

206

207

208

209

210

211

212

213

214

215

216

217

218

219

220

221

222

223

224

225

226

227

228

- Application of ML or DL in the detection of TEs (any class)

- Application of ML or DL in the classification of TEs (any class)

- Description of DNA coding schemes

- Use of ML or DL on similar genomic data

- Comparison of bioinformatics algorithms to ML or DL techniques

- Application of metrics to evaluate ML or DL algorithms for TEs or similar data

Exclusion criteria

- Do not use any ML or DL techniques

- Studies focused only on in vivo processes

- Studies that do not integrate any of the topics addressed in this review

After this selection process (Figure 1), we identified 35 relevant papers that were used to extract and summarize the information.

\section{Data extraction and synthesis}

In this stage, we first wholly read the selected publications (Table 2) to extract information to answer the research questions. Then, we registered the article into a data extraction card proposed by (Wen et al., 2012) with some adaptations to our study. The card contained information on publication identifier, year, publication name, related research questions, and the information itself.

In the final step, we synthesized all of the collected information and obtained evidence to answer the research questions. Interestingly, more than $50 \%$ of the selected studies were published between 2017 and 2019 (Figure 4), demonstrating a growing interest in this topic in the last years.

We identified 35 relevant publications after the systematic literature review process (see Table 2). These papers were published between 2009 and 2019. Among them, 77\% (27) were reported in journals, $17 \%$ (6) in conference proceedings, and $6 \%$ (2) as book sections (Figure 5A). The selected papers were published in 21 journals, of which ten 
229 focused on bioinformatics or computational biology, six on genomics or genetics, and 15 230 on other areas (Figure 5B).

\section{Benefits of ML over bioinformatics (Q1)}

232 There is much literature about applications of machine learning in bioinformatics (for example, reviewed in (Larrañaga et al., 2006)), showing improvements in many aspects such as genome annotation (Arango-López et al., 2017). In recent years, much bioinformatics software has been developed to detect TEs (Girgis, 2015) and, although they follow different strategies (such as homology-based, structure-based, de novo, and using comparative genomics), these lack sensitivity and specificity due to the polymorphic structures of TEs (Su, Gu \& Peterson, 2019). Loureiro et al. (Loureiro et al., 2013a) proved that ML could be used to improve the accuracy of TEs detection by combining results obtained by several conventional software and training a classifier using these results (Schietgat et al., 2018), (Loureiro et al., 2013b). Loureiro's work provided novel evidence for the use of ML in TEs, yet it did not use ML to obtain the predictions, making the results too dependent on traditional algorithms. Using the Random Forest algorithm, Schietgat et al. were able to improve results obtained by popular bioinformatics software (which followed a homology-based strategy) such as Censor, RepeatMasker, and LTRDigest (Schietgat et al., 2018) in the detection of LTR retrotransposons. The authors proposed a framework called TE-Learne ${ }^{\mathrm{LTR}}$, which outperformed LTRDigest in recall and RepeatMasker and Censor in terms of precision.

ML techniques also obtain better results than traditional methods regarding TEs classification. Using ML, it is possible to classify non-autonomous TEs (specifically derived from LTR retrotransposons) using features other than coding regions (which are commonly used in classification processes), including element length, LTR length, and ORF lengths (Arango-López et al., 2017). ML algorithms can distinguish between retroviral LTRs and SINEs (Short Interspersed Nuclear Elements) by combining a set of methods (Ashlock \& Datta, 2012), which is a complicated procedure in bioinformatics. Also, using hierarchical classification, ML-based methods obtain better results than wellknown homologous-based methods (specifically, BLASTn algorithm) (Nakano et al., 2017).

The advantages of using ML in bioinformatics include the discovery of entirely new information such as arrays of mobile genetic elements, new transposition unit boundaries (Tsafnat et al., 2011), and predicting new long noncoding RNA that are related to cancer (Zhang et al., 2018). Other applications include extracting discriminatory features for automatically determining functional properties of biological sequences (Kamath, De Jong \& Shehu, 2014), identifying DNA motifs, which is a difficult task in non-ML applications (Dashti \& Masoudi-Nejad, 2010), and automating specific processes like the identification of long non-coding RNAs (Ventola et al., 2017) and the classification of LTR retrotransposons (Arango-López et al., 2017). 
268 On the other hand, DL has been applied in biological areas such as genomics (for a

269

270

271

272

273

274

275

276

277

278

279

280

281

282

283

284

285

286

287

288

289

290

291

292

293

294

295

296

297

298

299

300

301

302

303

304

305

306

307

308 review see (Yue \& Wang, 2018)) proving to be promising (Yu, Yu \& Pan, 2017) due to the flexibility showed by deep neural networks. In (Eraslan et al., 2019), several applications in genomics are discussed such as variant calling, base calling for novel sequencing technologies, denoising ChIP-seq data (chromatin immunoprecipitation followed by sequencing), and enhancing $\mathrm{Hi}-\mathrm{C}$ data resolution (Chromosome conformation capture followed by pair-end sequencing). Also, some frameworks allow users to use GPUs as a complement for CPUs, achieving a faster execution of DL algorithms (Eraslan et al., 2019). Deep neural networks have also been used to improve the prediction of global enhancers, which was proven to be challenging using other computational tools (Kim et al., 2016).

$\mathrm{ML}$ and DL fields are supported by multiple companies and industry research groups, which anticipated the great benefits that artificial intelligence can contribute to genomics, human health (Eraslan et al., 2019), and major crops. Several papers using $\mathrm{ML}$ or $\mathrm{DL}$ techniques reported that TEs are associated with many human diseases (Zhang et al., 2013). For example, cancer-related long noncoding RNAs have higher SINE and LINE numbers than cancer-unrelated long noncoding RNAs (Zhang et al., 2018). Likewise, several types of epithelial cancers acquire somatic insertions of LINE-1 as they develop (mentioned in (Tang et al., 2017)). Moreover, the genes that confer antibiotic resistance (called $R$ genes) in bacteria are associated with TEs, and it is possible to detect them through ML (Tsafnat et al., 2011). Finally, although LTR retrotransposons are related to retroviruses such as HIV, ML algorithms can distinguish them from SINEs (Ashlock \& Datta, 2012). On the other hand, the human genome is composed of a considerable number of interspersed repeats, such as LINE-1 as one of the most abundant (Tang et al., 2017)), human endogenous retroviral sequences comprising 8-10 percent of the genome, and SINEs contributing with 11 percent. Meanwhile, protein-coding regions comprise only about 1.5 percent (Ashlock \& Datta, 2012).

Since TEs are under relatively low selection pressure and evolve more rapidly than coding genes (Rawal \& Ramaswamy, 2011), they undergo dynamic evolution. Moreover, insertions of other TEs (nested insertion), illegitimate and unequal recombination, cellular gene capture, and inter-chromosomal and tandem duplications (Garbus et al., 2015) make TEs classification and annotation a very complicated task (Bousios et al., 2012). Thus, conventional methods (such as bioinformatics) cannot obtain reliable results in TE detection and classification tasks.

In supervised problems, the process of feature extraction or selection is a crucial step for the performance of the entire architecture. In ML, the processes of selection of variables or characteristics must be carried out by a thematic expert. Deep network architectures, on the other hand, allow characteristics to be extracted in a nonlinear and automatic way. The hidden layers of deep neural networks transform these characteristics into intricate patterns relevant to the classification problem (Eraslan et

Peer) reviewing PDF | (2019:08:39972:2:1:NEW 21 Nov 2019) 
al., 2019). In the specific case of TEs, because they are DNA sequences, the extraction of characteristics is usually a too complex process due to a large amount of information, their unstructured form, and their sequentially. In this case, the deep neural networks provide new features that cannot be extracted manually. For example, convolutional neural networks can discover local patterns in sequential data such as pixels in an image or DNA (Zou et al., 2018). These patterns known as motifs have functions of great importance in the genome as promoters of genes and to be found in the LTR sequences of retrotransposons, in addition, if they are found in different places and under certain frequencies could be very useful to identify or classify TEs. Although motifs are essential for DNA classification problems, it is not enough to find the exact patterns, because DNA can undergo modifications or mutations and because specific motifs can function the same as others even if they do not have the same nucleotides. Another benefit of ML over bioinformatics is the use of labeled data to generate computational models. Currently, a few hundreds of plant genomes are available to train algorithms, but this number will increase significantly in the near future due to massive genome sequencing projects such as the $10 \mathrm{~K}$ plant project (https://db.cngb.org/10kp/) or the Earth BioGenome Project (https://www.earthbiogenome.org). This large amount of data will help to produce more accurate and reliable software thought ML and DL. Additional to available training data, some plant genomes are very interesting to identify and classify TEs following ML or DL approaches, due to their huge genome and their composition. As examples, sugarcane, maize, and barley have large genomes ( $3 \mathrm{~Gb}$, $2 \mathrm{~Gb}$, and $5.1 \mathrm{~Gb}$ respectively) that are composed mainly by repetitive sequences (up to $80 \%$, (Rahman et al., 2013)). On the other hand, the process of supervised training of $\mathrm{ML}$ algorithms provides another advantage when training a model that increases true positives and decreases false positives results. To improve this rate of performance, the hyperparameters of the models can be tuned using techniques such as search grid, which does an exhaustive search for the hyperparameters that produce the best accuracy and precision.

\section{ML architectures and algorithms currently used for TEs or similar data (Q2)}

ML has been applied in bioinformatics due to a large amount of data that has been generated. Ma and coworkers (Ma, Zhang \& Wang, 2014), review the application of ML in topics such as genome assembly, genomic variation detection, genome-wide association studies, and the in silico annotation of coding genomic loci. Particular focus has been given to loci that code for proteins, transposable elements, noncoding RNAs, miRNAs and targets, transcription factor binding sites, cis-regulatory elements, enhancer and silencer elements, and mRNA alternative splicing sites. Additionally, many frameworks have been developed to facilitate the implementation of ML algorithms in bioinformatics projects. Tools such as Scikit-learn, Weka, and several packages developed in $\mathrm{R}$ (for a complete list, see (Ma, Zhang \& Wang, 2014)) allow using ML-based techniques in biological areas. 
349 Most of the publications found in this review (Table 3 ) used supervised learning as the training mechanism $(84 \%, 21$ publications). We found only four publications $(16 \%)$ that used unsupervised learning (Figure 6A), which mainly addressed tasks of features selection and extraction and clustering of motif sequences.

Among the supervised learning algorithms used, random forest (RF) and support vector machine (SVM) are the most commonly found in the publications reviewed (Figure 6B). SVM is a widely used classifier, while RF can avoid overfitting and is insensitive to noise (Ashlock \& Datta, 2012), two features that are very useful in TE problems due to the high variability and lack of a general structure of TEs. On the other hand, we found only three publications that used HMM and, in the case of (Tsafnat et al., 2011) and (Zamani et al., 2013), HMMs are applied in the preprocessing step for other ML techniques. Hidden Markov Models (HMM) is another well-known technique in bioinformatics. RED, which de novo detects repeats, is the only software found that uses HMM as the primary tool (Girgis, 2015). Finally, 12 of 25 publications used more than one technique to compare results and select the most optimal or to improve the accuracy obtained.

Eight publications focused on the detection or classification of TEs, and all of them used supervised techniques. RF, decision trees (DT), and SVM are the most frequent algorithms. The use of preprocessing methods to extract features from DNA or RNA (Figure 7) was a common finding (for a review on the extraction and selection of features from biological sequences see (Kamath, De Jong \& Shehu, 2014)). For example, (Loureiro et al., 2013b), (Zamith Santos et al., 2018), and (Abrusan et al., 2009) used k-mer frequencies as features. On the contrary, (Schietgat et al., 2018), (Arango-López et al., 2017), (Loureiro et al., 2013a) used numerical and categorical features mainly based on structures. Other purposes of ML in TEs included detecting the boundaries of mobile elements (Tsafnat et al., 2011), identifying insertion sites of somatic LINEs insertions (Tang et al., 2017), and other mobile elements at the genome level (Rawal \& Ramaswamy, 2011), detecting aneuploidy in patients with cancer through LINEs (Douville et al., 2018), detecting conserved motifs in TIR elements (Su, Gu \& Peterson, 2019), distinguishing endogenous retroviral LTRs from SINEs (Ashlock \& Datta, 2012), and comparing multiple studies on transposon insertion sequencing (Hubbard et al., 2019). The last study used an unsupervised algorithm based on principal component analysis (PCA) to reduce the feature dimensions and improve the clustering analysis.

We also found publications that applied ML to other genomic data than TEs (these publications can be found in Table 2). Long non-coding RNAs (IncRNAs) are gaining attention because of critical biological functions suggested by recent studies (for a review see (Mercer, Dinger \& Mattick, 2009)). Some of the ML applications found included the detection of cancer-related IncRNA (Zhang et al., 2018), the discrimination of circular RNAs from other IncRNAs (Chen et al., 2018), and selection of the most informative features of IncRNA (Ventola et al., 2017). Other applications in the RNA field address the identification and clustering of RNA structure motifs (Smith et al., 2017), 
390 prediction of microRNA precursors (Ding, Zhou \& Guan, 2010), prediction of piRNA 391 (Brayet et al., 2014), and classification of small non-coding RNAs (Ryvkin et al., 2014).

392 Although TEs are DNA molecules, the techniques applied to IncRNA could be

393 extrapolated to TEs since they are composed of long non-coding regions containing motifs. For example, LTR retrotransposons have two highly similar characteristic Long Terminal Repeats (LTR) that usually contain Short Inverted Repeat (SIR) motifs TG-5' and 3'-CA at both ends (Mascagni et al., 2015), (Yin et al., 2013), as well as one to three AT-rich regions with one or two TATA-boxes and a polyadenylation signal (AATAAA motif) (Benachenhou et al., 2013), (Gao et al., 2012). Consequently, the approaches implemented in (Zamani et al., 2013) can be beneficial for predicting patterns inside TEs, yielding better results in classification processes.

401

402

403

404

405

406

407

408

409

410

411

412

413

414

415

416

417

418

419

420

421

422

423

424

425

426

427

428

429

430

Regarding DL, we found five articles that addressed TE classification (Nakano et al., 2018b), the detection of long intergenic non-coding RNA (lincRNA) using different coding schemes and outperforming SVM results (Yu, Yu \& Pan, 2017), the use of DL to predict enhancers based on chromatin features (Kim et al., 2016), and the use of convolutional neural networks to classify TEs (da Cruz et al., 2019). Lastly, the fifth article reviewed the applications of DL in genomics (Eraslan et al., 2019).

The first ideas on deep artificial neural networks (DNN) were discussed in the 1990s, although mature concepts on the subject matter appeared in the 2000s (Yu, Yu \& Pan, 2017). Auto-encoders, which can perform non-linear dimensionality reduction by training a multilayer neural network with a small central layer to reconstruct high-dimensional input vectors (Zou et al., 2018), have been used by Yu and coworkers (Yu, Yu \& Pan, 2017) with a setting of two layers. They demonstrated better results than SVM in the prediction of IncRNA. Moreover, other publications have reported better results from DL compared to conventional ML techniques. In (Eraslan et al., 2019), the authors reviewed several DL architectures used in genomics (Table 4), showing improved predictive performance over ML methods, including Logistic Regression, Decision Trees or Random Forest. Since no publications were found addressing TE detection, the application of auto-encoders can be a novel way to predict TEs with long non-coding regions (such as LTR retrotransposons).

One of the most useful characteristics of DL architectures is that DNN can automatically learn non-linear features since each layer uses multiple linear models, and the outputs are transformed by non-linear activation functions, such as sigmoid functions or rectified-linear unit (ReLU) (Eraslan et al., 2019). This process could facilitate classification tasks that include, for instance, distinguishing superfamilies of LTR retrotransposons (Copia and Gypsy). Furthermore, (Nakano et al., 2018b) used these advantages to improve the hierarchical classification of TEs (Figure 8) through fully connected neural networks and using k-mer frequencies as features.

Advances in DL can be attributed to the use of frameworks, which facilitate the implementation of crucial operations required to build and train neural networks, such as Keras (Chollet \& others, 2015), tensorFlow (Abadi et al., 2016), Theano (Bergstra et al., 
431 2011) or Pytorch (Paszke et al., 2017). These operations include matrix multiplication,

432

433

434

435

436

437

438

439

440

441

442

443

444

445

446

447

448

449

450

451

452

453

454

455

456

457

458

459

460

461

462

463

464

465

466

467

468

469

470

471 convolution, and automatic differentiation (Eraslan et al., 2019), allowing users to specify their models more easily and quickly. Another advantage is that users do not need to parallelize their codes since frameworks like tensorFlow can do it automatically.

Convolutional neural networks (CNN) have been widely used in genomics. Most of the publications shown in Table 4 take advantage of the ability of CNNs to extract high-level features directly from sequences (in most cases, using one-hot codification). These features were then passed to other layers (i.e. fully connected layers) to calculate the final results. Recently, CNNs have been applied to the classification of TEs and have shown better results than conventional bioinformatics software such as PASTEC and REPCLASS. Accordingly, benefits can be gained from the use of this kind of neural networks (da Cruz et al., 2019) (Figure 9). Since TEs display different structural features, specific motifs, and promoters, CNNs can find features that are not calculable with conventional methods. This ability can provide useful information to researchers interested in understanding the diversity and characteristics of TEs, as well as improving the detection and classification of these elements. Other architectures such as recurrent neural networks (RNNs) have been applied in distinct tasks in genomics, such as the prediction of binding sequences. A crucial feature of this kind of DNNs is the implementation of memory. An application of RNNs in TEs is the identification of boundaries, which, in most orders, are composed of short duplications at both ends (Target Site Duplications -TSD-) and, in some orders, (i.e. LTR retrotransposons and TIR DNA transposons) of non-coding repeat regions (long terminal repeats for LTR retrotransposons and terminal inverted repeat for TIR DNA transposons). On the other hand, since nucleotides from TEs are used as input, it is likely to have more variables than individuals, leading to overfitting in the training steps. Thus, auto-encoders can be used to reduce the number of features in a non-linear way, helping to overcome this issue.

To summarize, the ML techniques already used in TEs are mainly RF, DT, and SVM. Although most publications use supervised learning, some papers can be found using unsupervised learning, mainly for extracting and selecting characteristics. Only two articles were found that applied DL (one publication used FNN and the other CNN) to the classification of TE, but they aimed to predict TE orders. Therefore, more research is needed on DL approaches.

\section{Parameters and metrics applied in algorithms and architectures (Q3)}

To ensure that ML architectures do not exclusively learn patterns of the training dataset, there are several techniques used to split information into different datasets, such as the hold-out and k-cross-validation methods. These methods should be used in problems with information of any kind. Particularly with data of genomic origin, k-cross-validation seems to be the most popular (Ma, Zhang \& Wang, 2014). Using $k=10$, different studies demonstrated high accuracies for long non-coding RNAs (Chen et al., 2018; Zhang et al., 2018), for selecting features for classification of biological sequences (Kamath, De

Peer) reviewing PDF | (2019:08:39972:2:1:NEW 21 Nov 2019) 
472 Jong \& Shehu, 2014), analyzing insertion sites of somatic LINEs in ovarian cancer 473 (Tang et al., 2017), and improving the classification of TEs (Loureiro et al., 2013b; 474 Nakano et al., 2018b). Meanwhile, $k=5$ was used by (Segal et al., 2018) to infer the 475 importance of specific genes for growth under laboratory conditions.

476 In ML tasks, it is essential to have curated datasets (Loureiro et al., 2013a). The quality 477 of TE and other genomic datasets is complex to evaluate, and their nature can influence 478 the final results. Databases such as PGSB contain genomic TE sequences from many 479 species, while repetDB or RepBase comprise consensus sequences of TEs. Ashlock 480 and Datta (2012) proposed that, although consensus sequences have been used to 481 train several ML algorithms (i.e. TEclass (Abrusan et al., 2009) and REPCLASS 482 (Feschotte et al., 2009)), this type of datasets caused poor results. The authors also 483 recommended taking this into account for ML projects in genomics.

484 A key aspect in the field of artificial intelligence is the calculation of metrics that 485 represent the performance of the algorithms and architectures. Classification or detection tasks mostly rely on defining two classes, positive and negative. Accordingly, the predicted results are marked as true positives (TP) if they were classified as positive and are contained in the positive class, while as false negatives (FN) if they were rejected but did not belong to the negative class. Also, candidates that appear in the negative set that were classified as positives are counted as false positives (FP), and all others are classified as true negatives (TN) (Tsafnat et al., 2011). Most metrics are based on the frequencies of these markers (Table 5).

The most popular metrics in ML projects are accuracy, sensitivity, specificity, precision, recall, F-score, and ROC curves (Ma, Zhang \& Wang, 2014). However, these are not appropriate in every case, especially when the positive and negative data sets are unbalanced. For example, ROC curves are not used in TE classification, because only a small portion of the genome contains certain TE superfamilies. In this case, it is more interesting to recognize positive results than predict negative candidates correctly through precision recall-curves (PRC) (Schietgat et al., 2018). Also, instead of using accuracy, AUC and PRC are used for the feature construction and selection of classification of biological sequences (Kamath, De Jong \& Shehu, 2014) and the identification of long non-coding RNA (Ventola et al., 2017).

In hierarchical classification problems, there is no consensus on which metrics should be used (Zamith Santos et al., 2018), although a set of evaluation measures have been proposed such as hierarchical Precision (hP), hierarchical Recall $(\mathrm{hR})$, and hierarchical F-measure (hF) (Figure 10) (Nakano et al., 2017). Since TE classification systems follow a hierarchical topology, these metrics can contribute to improving the measurement of algorithms and architectures to classify TEs.

In brief, because the detection and classification of TE can be covered from different approaches (binary problems, multi classes or hierarchical classification), multiple metrics can be applied. However, it is necessary to use those metrics that are not 
512 affected by unbalanced data sets, which is a problem linked to these types of data.

513 Although in genomics, the k-cross-validation method is the most common, the k-value

514 depends on the size of the training dataset. The papers evaluated in this review used

515 values of $k=5$ and 10 . On the other hand, it was found that the nature of the data

516 (genomic sequences or consensus) affects the performance of ML algorithms, so some

517 authors recommend the use of genomic sequences.

518 Most used DNA coding schemes (Q4)

519 One of the most critical tasks in ML algorithms is correct data representation. In contrast

520

521

522

523

524

525

526

527

528

529

530

531

532

533

534

535

536

537

538

539

540

541

542

543

544

545

546

547

548

549 to other datasets, DNA nucleotide sequences are human-readable characters, C, T, A, and $G$, so it is necessary to encode them in a machine-readable form ( $Y u, Y u \&$ Pan, 2017). Table 6 shows coding schemes that can be applied to representing nucleotides by different approaches. Using deep neural networks, (Yu, Yu \& Pan, 2017) demonstrated that the complementary scheme had the best performance, while the other schemes achieved similar predictive rates.

In some cases, input sequences need to be first transformed into k-mer counts (Zamith Santos et al., 2018). For example, for distinguishing between Endogenous Retroviral LTRs from SINEs, the dinucleotide (2-mer) "TT" appears more frequently in LTRs than in SINEs and LTRs have more TAs, TGs, As, and Gs before their first $C$ than SINEs. These k-mer features add more information than the raw DNA sequences in the classification process (Ashlock \& Datta, 2012). Additionally, k-mer frequencies of $\mathrm{k}=$ 2,3,4 have been used (Nakano et al., 2017, 2018a) for TE classification through DL. Other examples that apply k-mer occurrences to sequence transformation are the prediction of DNA promoter regions, cis sites, HS sites, splice sites, among others (reviewed in (Kamath, De Jong \& Shehu, 2014)).

Recently, an innovative way to convert sequences into numerical representations was proposed by (Jaiswal \& Krishnamachari, 2019). The authors considered three physicochemical properties, namely, average hydrogen bonding energy per base pair (bp), stacking energy (per bp), and solvation energy (per bp), which are calculated by taking the first di-nucleotide and then moving a sliding window, one base at a time. Accordingly, a classification task was performed using this process. Although this classification was carried out on the Saccharomyces cerevisiae genome, it can be extrapolated to other species with distinct types of TEs.

To summarize, the use of k-mers frequencies seems to be more common and get better results in $\mathrm{ML}$ algorithms. On the other hand, in $\mathrm{DL}$ architectures, they mainly use the one-hot coding scheme because the extraction is carried out automatically. Interestingly, the problem of TEs detection could be addressed using the physicochemical characteristics of the di-nucleotides.

\section{Conclusions and future work}

Peer) reviewing PDF | (2019:08:39972:2:1:NEW 21 Nov 2019) 
$550 \mathrm{ML}$ is a powerful tool that can extract patterns, novel information, and relations from 551 labeled data (supervised learning) or unlabeled data (unsupervised learning). These 552 artificial intelligence approaches improve complex tasks and automate processes that 553 would otherwise be done manually. Although ML and DL fields have been applied in 554 areas such as genomics, human health, face recognition, and many others, the use of $555 \mathrm{ML}$ and DL in TEs is still limited. This is especially true for deep neural networks such 556 as convolutional neural networks, which could provide opportunities to extract features 557 that are undetected by conventional bioinformatics methods. Although TE detection and 558 classification are very complex tasks because of the variability of these elements, there 559 are databases with thousands of TE sequences that have been recently released.

560 These databases can contribute training sets for obtaining better and generalized 561 models to improve the accuracy and reliability of the results. TEs are associated with 562 many aspects in humans (such as diseases) and plants (like intra and inter-species 563 diversity, adaptation to the environment, among others). Therefore, a broader 564 understanding of these elements can provide better knowledge of our genomes as well 565 as about important crops. Accordingly, this can lead to faster and reliable diagnostic and 566 clinical treatments in diseases like cancer and more resistant and productive crops.

567 Unquestionably, ML and DL can support novel methods to detect, classify, and analyze 568 repeated sequences. To date, there are few publications on the application of DL in 569 TEs, so the door is open to proposing innovative methodologies and architectures.

Taking into account this systematic review of literature, we propose the following ideas as future work:

- To use Autoencoders to increase the size of the training datasets (data augmentation) on the TEs already classified and validated by the bioinformatics community, in order to obtain a better generalization of the ML and $\mathrm{DL}$ algorithms.

- To use sets of simultaneous classifiers (SVM, RF, DT, LR, among others) in order to generate separation frontiers of classes more adapted to the nature of this type of problem and thus be able to increase the percentages of precision in the detection and classification of TEs.

- To train new artificial neural network architectures using transfer learning techniques from the results obtained by the neural networks proposed in the literature.

- To use techniques of selection of characteristics (Random Forest) or reduction of dimensionality (PCA) in order to diminish the databases' complexity and to increase the percentages of precision in the detection and classification of TEs.

\section{4}

585

586

587

588

\section{Acknowledgements}

The authors thanks the Universidad Autónoma de Manizales, Manizales, Colombia, for support and covering publication fees under project 589-089 and the LMI BIO-INCA for supporting Romain Guyot.

\section{References}


589

Abadi M, Barham P, Chen J, Chen Z, Davis A, Dean J, Devin M, Ghemawat S, Irving G, Isard M, others. 2016. Tensorflow: A system for large-scale machine learning. In: 12th USENIX Symposium on Operating Systems Design and Implementation (OSDI 16). 265-283.

Abrusan G, Grundmann N, DeMester L, Makalowski W. 2009. TEclass--a tool for automated classification of unknown eukaryotic transposable elements. Bioinformatics 25:1329-1330. DOI: 10.1093/bioinformatics/btp084.

Arango-López J, Orozco-Arias S, Salazar JA, Guyot R. 2017. Application of Data Mining Algorithms to Classify Biological Data: The Coffea canephora Genome Case. In: 156-170. DOI: 10.1007/978-3-319-66562-7_12.

Ashlock W, Datta S. 2012. Distinguishing endogenous retroviral LTRs from SINE elements using features extracted from evolved side effect machines. IEEE/ACM Transactions on Computational Biology and Bioinformatics 9:1676-1689. DOI: 10.1109/TCBB.2012.116.

Benachenhou F, Sperber GO, Bongcam-Rudloff E, Andersson G, Boeke JD, Blomberg J. 2013. Conserved structure and inferred evolutionary history of long terminal repeats (LTRs). MOBILE DNA 4. DOI: 10.1186/1759-8753-4-5.

Bergstra J, Bastien F, Breuleux O, Lamblin P, Pascanu R, Delalleau O, Desjardins G, Warde-Farley D, Goodfellow I, Bergeron A, others. 2011. Theano: Deep learning on gpus with python. In: NIPS 2011, BigLearning Workshop, Granada, Spain. 1-48.

Bousios A, Minga E, Kalitsou N, Pantermali M, Tsaballa A, Darzentas N. 2012. MASiVEdb: the Sirevirus Plant Retrotransposon Database. BMC Genomics 13:158. DOI: 10.1186/1471-2164-13-158.

Brayet J, Zehraoui F, Jeanson-Leh L, Israeli D, Tahi F. 2014. Towards a piRNA prediction using multiple kernel fusion and support vector machine. Bioinformatics (Oxford, England) 30:i364-70. DOI: 10.1093/bioinformatics/btu441.

de Castro Nunes R, Orozco-Arias S, Crouzillat D, Mueller LA, Strickler SR, Descombes P, Fournier C, Moine D, de Kochko A, Yuyama PM, Vanzela ALL, Guyot R. 2018. Structure and Distribution of Centromeric Retrotransposons at Diploid and Allotetraploid Coffea Centromeric and Pericentromeric Regions. Frontiers in Plant Science. DOI: 10.3389/fpls.2018.00175.

Ceballos D, López-Álvarez D, Isaza G, Tabares-Soto R, Orozco-Arias S, Ferrin C. 2019. A Machine Learning-based Pipeline for the Classification of CTX-M in Metagenomics Samples. Processes 7:235. DOI: 10.3390/pr7040235.

Chen L, Zhang Y-H, Huang G, Pan X, Wang S, Huang T, Cai Y-D. 2018. Discriminating cirRNAs from other IncRNAs using a hierarchical extreme learning machine $(\mathrm{H}-$ ELM) algorithm with feature selection. Molecular Genetics and Genomics 293:137149. DOI: $10.1007 / \mathrm{s} 00438-017-1372-7$.

Chollet F, others. 2015. Keras.

Choulet F, Alberti A, Theil S, Glover N, Barbe V, Daron J, Pingault L, Sourdille P, 
629

630

631

632

633

634

635

636

637

638

639

640

641

642

643

644

645

646

647

648

649

650

651

652

653

654

655

656

657

658

659

660

661

662

663

664

665

666

667

668

Couloux A, Paux E, others. 2014. Structural and functional partitioning of bread wheat chromosome 3B. Science 345:1249721.

da Cruz MHP, Saito PTM, Paschoal AR, Bugatti PH. 2019. Classification of Transposable Elements by Convolutional Neural Networks. In: Lecture Notes in Computer Science. Springer International Publishing, 157-168. DOI: 10.1201/9781420049138.

Dashti TH, Masoudi-Nejad A. 2010. Mining Biological Repetitive Sequences Using Support Vector Machines and Fuzzy SVM. IRANIAN JOURNAL OF CHEMISTRY \& CHEMICAL ENGINEERING-INTERNATIONAL ENGLISH EDITION 29:1-17.

Ding J, Zhou S, Guan J. 2010. MiRenSVM: towards better prediction of microRNA precursors using an ensemble SVM classifier with multi-loop features. BMC Bioinformatics 11:S11. DOI: 10.1186/1471-2105-11-S11-S11.

Douville C, Springer S, Kinde I, Cohen JD, Hruban RH, Lennon AM, Papadopoulos N, Kinzler KW, Vogelstein B, Karchin R. 2018. Detection of aneuploidy in patients with cancer through amplification of long interspersed nucleotide elements (LINEs). Proceedings of the National Academy of Sciences of the United States of America 115:1871-1876. DOI: 10.1073/pnas.1717846115.

Eraslan G, Avsec Ž, Gagneur J, Theis FJ. 2019. Deep learning: new computational modelling techniques for genomics. Nature Reviews Genetics. DOI: 10.1038/s41576-019-0122-6.

Feschotte C, Keswani U, Ranganathan N, Guibotsy ML, Levine D. 2009. Exploring repetitive DNA landscapes using REPCLASS, a tool that automates the classification of transposable elements in eukaryotic genomes. Genome biology and evolution 1:205-20. DOI: 10.1093/gbe/evp023.

Franco-Bedoya O, Ameller D, Costal D, Franch X. 2017. Open source software ecosystems: A Systematic mapping. Information and Software Technology 91:160185. DOI: 10.1016/j.infsof.2017.07.007.

Gao D, Jimenez-Lopez JC, Iwata A, Gill N, Jackson SA. 2012. Functional and structural divergence of an unusual LTR retrotransposon family in plants. PloS one 7:e48595. DOI: 10.1371 /journal.pone.0048595.

Garbus I, Romero JR, Valarik M, Vanžurová H, Karafiátová M, Cáccamo M, Doležel J, Tranquilli G, Helguera M, Echenique V. 2015. Characterization of repetitive DNA landscape in wheat homeologous group 4 chromosomes. BMC Genomics 16:375. DOI: 10.1186/s12864-015-1579-0.

Girgis HZ. 2015. Red: an intelligent, rapid, accurate tool for detecting repeats de-novo on the genomic scale. BMC Bioinformatics 16:227. DOI: 10.1186/s12859-0150654-5.

Grandbastien M-A. 2015. LTR retrotransposons, handy hitchhikers of plant regulation and stress response. Biochimica et biophysica acta 1849:403-16. DOI: 10.1016/j.bbagrm.2014.07.017. 
669

670

671

672

673

674

675

676

677

678

679

680

681

682

683

684

685

686

687

688

689

690

691

692

693

694

695

696

697

698

699

700

701

702

703

704

705

706

707

Hubbard TP, D'Gama JD, Billings G, Davis BM, Waldor MK. 2019. Unsupervised Learning Approach for Comparing Multiple Transposon Insertion Sequencing Studies. mSphere 4. DOI: 10.1128/mSphere.00031-19.

Jaiswal AK, Krishnamachari A. 2019. Physicochemical property based computational scheme for classifying DNA sequence elements of Saccharomyces cerevisiae. Computational Biology and Chemistry 79:193-201. DOI: https://doi.org/10.1016/j.compbiolchem.2018.12.014.

Kamath U, De Jong K, Shehu A. 2014. Effective automated feature construction and selection for classification of biological sequences. PloS one 9:e99982. DOI: 10.1371/journal.pone.0099982.

Kim SG, Harwani M, Grama A, Chaterji S. 2016. EP-DNN: A Deep Neural NetworkBased Global Enhancer Prediction Algorithm. SCIENTIFIC REPORTS 6. DOI: 10.1038/srep38433.

Kitchenham B, Charters S. 2007. Guidelines for performing Systematic Literature Reviews in Software Engineering.

Larrañaga P, Calvo B, Santana R, Bielza C, Galdiano J, Inza I, Lozano JA, Armañanzas R, Santafé G, Pérez A, Robles V. 2006. Machine learning in bioinformatics. Briefings in Bioinformatics 7:86-112. DOI: 10.1093/bib/bbk007.

Loureiro T, Camacho R, Vieira J, Fonseca NA. 2013a. Boosting the Detection of Transposable Elements Using Machine Learning. In: 85-91. DOI: 10.1007/978-3319-00578-2_12.

Loureiro T, Camacho R, Vieira J, Fonseca NA. 2013b. Improving the performance of Transposable Elements detection tools. Journal of integrative bioinformatics 10:231. DOI: 10.2390/biecoll-jib-2013-231.

Ma C, Zhang HH, Wang X. 2014. Machine learning for Big Data analytics in plants. Trends in Plant Science 19:798-808. DOI: 10.1016/j.tplants.2014.08.004.

Mascagni F, Barghini E, Giordani T, Rieseberg LH, Cavallini A, Natali L. 2015. Repetitive DNA and Plant Domestication: Variation in Copy Number and Proximity to Genes of LTR-Retrotransposons among Wild and Cultivated Sunflower (Helianthus annuus) Genotypes. Genome biology and evolution 7:3368-82. DOI: 10.1093/gbe/evv230.

Mercer TR, Dinger ME, Mattick JS. 2009. Long non-coding RNAs: insights into functions. Nature reviews genetics 10:155.

Mjolsness E, DeCoste D. 2001. Machine learning for science: state of the art and future prospects. science 293:2051-2055.

Moher D, Liberati A, Tetzlaff J, Altman DG. 2009. Preferred reporting items for systematic reviews and meta-analyses: the PRISMA statement. Annals of internal medicine 151:264-269.

Mustafin RN, Khusnutdinova EK. 2018. The Role of Transposons in Epigenetic 
727

728

729

730

731

732

733

734

735

736

737

738

739

740

741

742

743

744

745

746

747

Regulation of Ontogenesis. Russian Journal of Developmental Biology 49:61-78. DOI: $10.1134 / \mathrm{S} 1062360418020066$.

Nakano FK, Martiello Mastelini S, Barbon S, Cerri R. 2018a. Stacking methods for hierarchical classification. In: Proceedings - 16th IEEE International Conference on Machine Learning and Applications, ICMLA 2017. 289-296. DOI: 10.1109/ICMLA.2017.0-145.

Nakano FK, Mastelini SM, Barbon S, Cerri R. 2018b. Improving Hierarchical Classification of Transposable Elements using Deep Neural Networks. In: Proceedings of the International Joint Conference on Neural Networks. Rio de Janeiro, Brazil,.

Nakano FK, Pinto WJ, Pappa GL, Cerri R. 2017. Top-down strategies for hierarchical classification of transposable elements with neural networks. In: Proceedings of the International Joint Conference on Neural Networks. Anchorage, AK, United states, 2539-2546.

Neumann P, Novák P, Hoštáková N, MacAs J. 2019. Systematic survey of plant LTRretrotransposons elucidates phylogenetic relationships of their polyprotein domains and provides a reference for element classification. Mobile DNA 10:1-17. DOI: 10.1186/s13100-018-0144-1.

Orozco-Arias S, Isaza G, Guyot R. 2019. Retrotransposons in Plant Genomes: Structure, Identification, and Classification through Bioinformatics and Machine Learning. International Journal of Molecular Sciences 20:3837. DOI: 10.3390/ijms20153837.

Orozco-arias S, Liu J, Id RT, Ceballos D, Silva D, Id D, Ming R, Guyot R. 2018. Inpactor, Integrated and Parallel Analyzer and Classifier of LTR Retrotransposons and Its Application for Pineapple LTR Retrotransposons Diversity and Dynamics. Biology. DOI: 10.3390/biology7020032.

Ou S, Chen J, Jiang N. 2018. Assessing genome assembly quality using the LTR Assembly Index (LAI). Nucleic Acids Research:1-11. DOI: 10.1093/nar/gky730.

Paszke A, Gross S, Chintala S, Chanan G, Yang E, DeVito Z, Lin Z, Desmaison A, Antiga L, Lerer A. 2017. Automatic differentiation in pytorch.

Piégu B, Bire S, Arensburger P, Bigot Y. 2015. A survey of transposable element classification systems - A call for a fundamental update to meet the challenge of their diversity and complexity. Molecular Phylogenetics and Evolution 86:90-109. DOI: 10.1016/j.ympev.2015.03.009.

Rahman AYA, Usharraj AO, Misra BB, Thottathil GP, Jayasekaran K, Feng Y, Hou S, Ong SY, Ng FL, Lee LS, others. 2013. Draft genome sequence of the rubber tree Hevea brasiliensis. BMC genomics 14:75.

Rawal K, Ramaswamy R. 2011. Genome-wide analysis of mobile genetic element insertion sites. Nucleic acids research 39:6864-78. DOI: 10.1093/nar/gkr337.

Ryvkin P, Leung YY, Ungar LH, Gregory BD, Wang L-S. 2014. Using machine learning 
and high-throughput RNA sequencing to classify the precursors of small noncoding RNAs. Methods 67:28-35. DOI: https://doi.org/10.1016/j.ymeth.2013.10.002.

Schietgat L, Vens C, Cerri R, Fischer CN, Costa E, Ramon J, Carareto CMA, Blockeel H. 2018. A machine learning based framework to identify and classify long terminal repeat retrotransposons. PLoS computational biology 14:e1006097. DOI: 10.1371/journal.pcbi.1006097.

Segal ES, Gritsenko V, Levitan A, Yadav B, Dror N, Steenwyk JL, Silberberg Y, Mielich K, Rokas A, Gow NAR, Kunze R, Sharan R, Berman J. 2018. Gene Essentiality Analyzed by In Vivo Transposon Mutagenesis and Machine Learning in a Stable Haploid Isolate of Candida albicans. mBio 9. DOI: 10.1128/mBio.02048-18.

Smith MA, Seemann SE, Quek XC, Mattick JS. 2017. DotAligner: identification and clustering of RNA structure motifs. Genome Biology 18:244. DOI: 10.1186/s13059017-1371-3.

Su W, Gu X, Peterson T. 2019. TIR-Learner, a New Ensemble Method for TIR Transposable Element Annotation, Provides Evidence for Abundant New Transposable Elements in the Maize Genome. Molecular Plant 12:447-460. DOI: 10.1016/j.molp.2019.02.008.

Tabares-Soto R, Ramos-Pollan R, Isaza G. 2019. Deep Learning Applied to Steganalysis of Digital Images: A Systematic Review. IEEE Access 4:1-1. DOI: 10.1109/ACCESS.2019.2918086.

Tang Z, Steranka JP, Ma S, Grivainis M, Rodić N, Huang CRL, Shih I-M, Wang T-L, Boeke JD, Fenyö D, Burns KH. 2017. Human transposon insertion profiling: Analysis, visualization and identification of somatic LINE-1 insertions in ovarian cancer. Proceedings of the National Academy of Sciences 114:E733-E740. DOI: 10.1073/pnas.1619797114.

Tsafnat G, Setzermann P, Partridge SR, Grimm D. 2011. Computational inference of difficult word boundaries in DNA languages. In: ACM International Conference Proceeding Series. Barcelona, Spain, IEEE; Kyranova Ltd, Center for TelelnFrastruktur (.

Ventola GMM, Noviello TMR, D’Aniello S, Spagnuolo A, Ceccarelli M, Cerulo L. 2017. Identification of long non-coding transcripts with feature selection: a comparative study. BMC Bioinformatics 18:187. DOI: 10.1186/s12859-017-1594-z.

Wen J, Li S, Lin Z, Hu Y, Huang C. 2012. Systematic literature review of machine learning based software development effort estimation models. Information and Software Technology 54:41-59. DOI: 10.1016/j.infsof.2011.09.002.

Wheeler TJ, Clements J, Eddy SR, Hubley R, Jones TA, Jurka J, Smit AFA, Finn RD. 2012. Dfam: a database of repetitive DNA based on profile hidden Markov models. Nucleic acids research 41:D70--D82.

Wicker T, Sabot F, Hua-Van A, Bennetzen JL, Capy P, Chalhoub B, Flavell A, Leroy P, 
788

789

790

791

792

793

794

795

796

797

798

799

800

801

802

803

804

805

806

807

808

809

810

811

812

813

Morgante M, Panaud O, Paux E, SanMiguel P, Schulman AH. 2007. A unified classification system for eukaryotic transposable elements. Nature Reviews Genetics 8:973-982. DOI: 10.1038/nrg2165.

Yin H, Liu J, Xu Y, Liu X, Zhang S, Ma J, Du J. 2013. TARE1, a mutated Copia-like LTR retrotransposon followed by recent massive amplification in tomato. PloS one 8:e68587. DOI: 10.1371/journal.pone.0068587.

Yu N, Yu Z, Pan Y. 2017. A deep learning method for lincRNA detection using autoencoder algorithm. BMC Bioinformatics 18:511. DOI: 10.1186/s12859-017-1922-3.

Yue T, Wang H. 2018. Deep Learning for Genomics: A Concise Overview. :1-40.

Zamani N, Russell P, Lantz H, Hoeppner MP, Meadows JR, Vijay N, Mauceli E, di Palma F, Lindblad-Toh K, Jern P, Grabherr MG. 2013. Unsupervised genome-wide recognition of local relationship patterns. BMC Genomics 14:347. DOI: 10.1186/1471-2164-14-347.

Zamith Santos B, Trindade Pereira G, Kenji Nakano F, Cerri R. 2018. Strategies for selection of positive and negative instances in the hierarchical classification of transposable elements. In: Proceedings - 2018 Brazilian Conference on Intelligent Systems, BRACIS 2018. 420-425. DOI: 10.1109/BRACIS.2018.00079.

Zhang Y, Babaian A, Gagnier L, Mager DL. 2013. Visualized Computational Predictions of Transcriptional Effects by Intronic Endogenous Retroviruses. PLOS ONE 8:e71971. DOI: 10.1371/journal.pone.0071971.

Zhang X, Wang J, Li J, Chen W, Liu C. 2018. CRIncRC: a machine learning-based method for cancer-related long noncoding RNA identification using integrated features. BMC Medical Genomics 11:120. DOI: 10.1186/s12920-018-0436-9.

Zou J, Huss M, Abid A, Mohammadi P, Torkamani A, Telenti A. 2018. A primer on deep learning in genomics. Nature Genetics. DOI: 10.1038/s41588-018-0295-5. 
Figure 1

PRISMA flow diagram

PRISMA flow chart for search and article screening process. From: Moher et al. (2009).

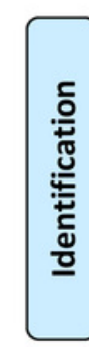

Records identified through database searching

$$
(n=403)
$$

Additional records identified through other sources

$(n=0)$

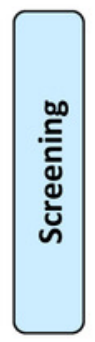

Records after duplicates removed

$$
(n=371)
$$
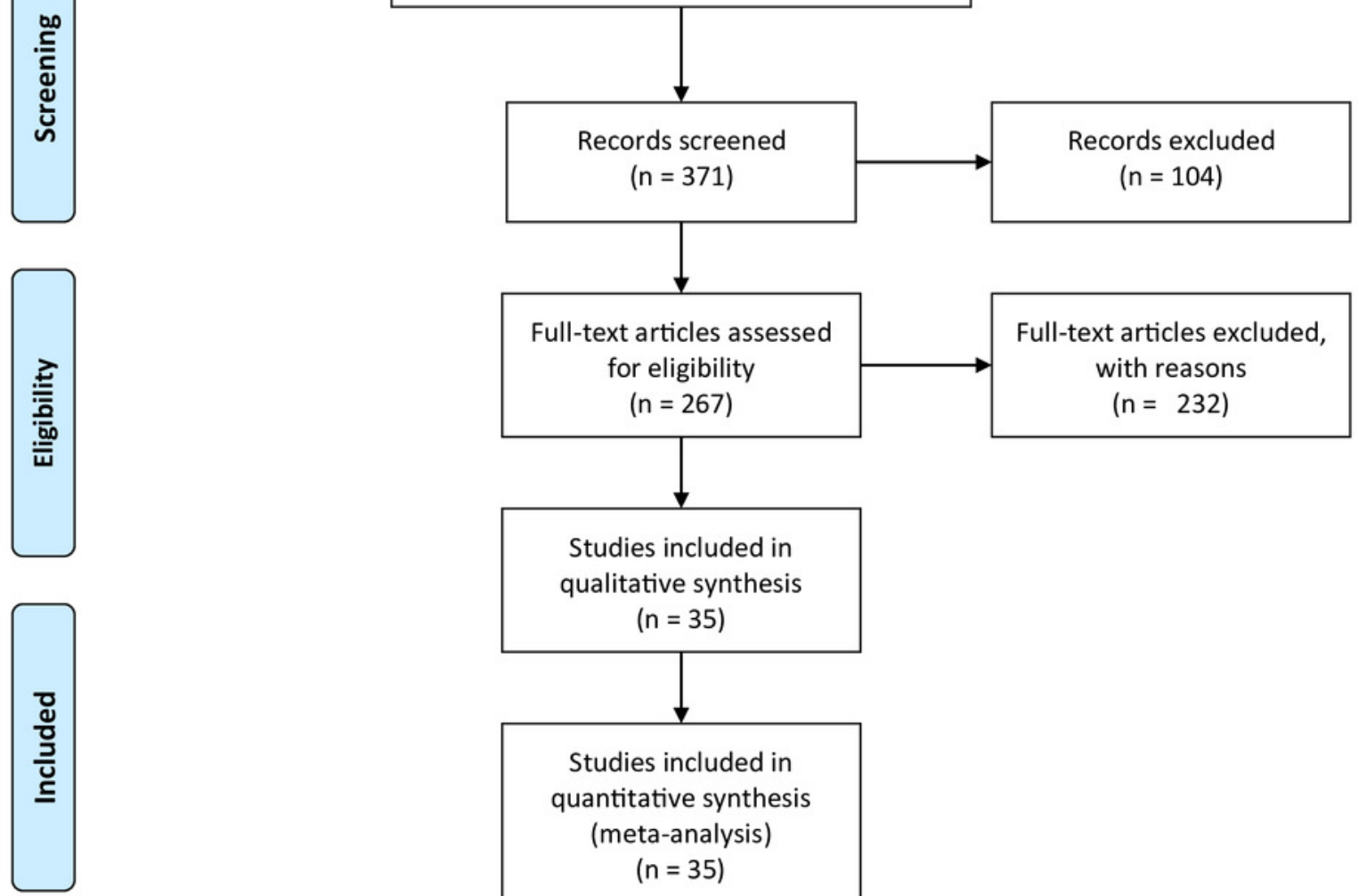

Studies included in qualitative synthesis ( $n=35)$

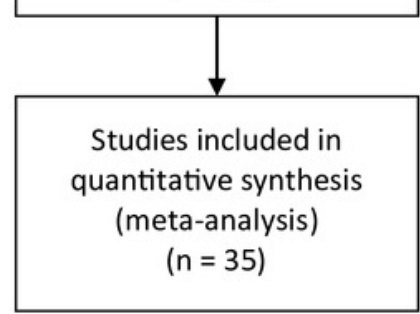


Figure 2

Stages of the systematic literature review process. Based on (Wen et al., 2012). 


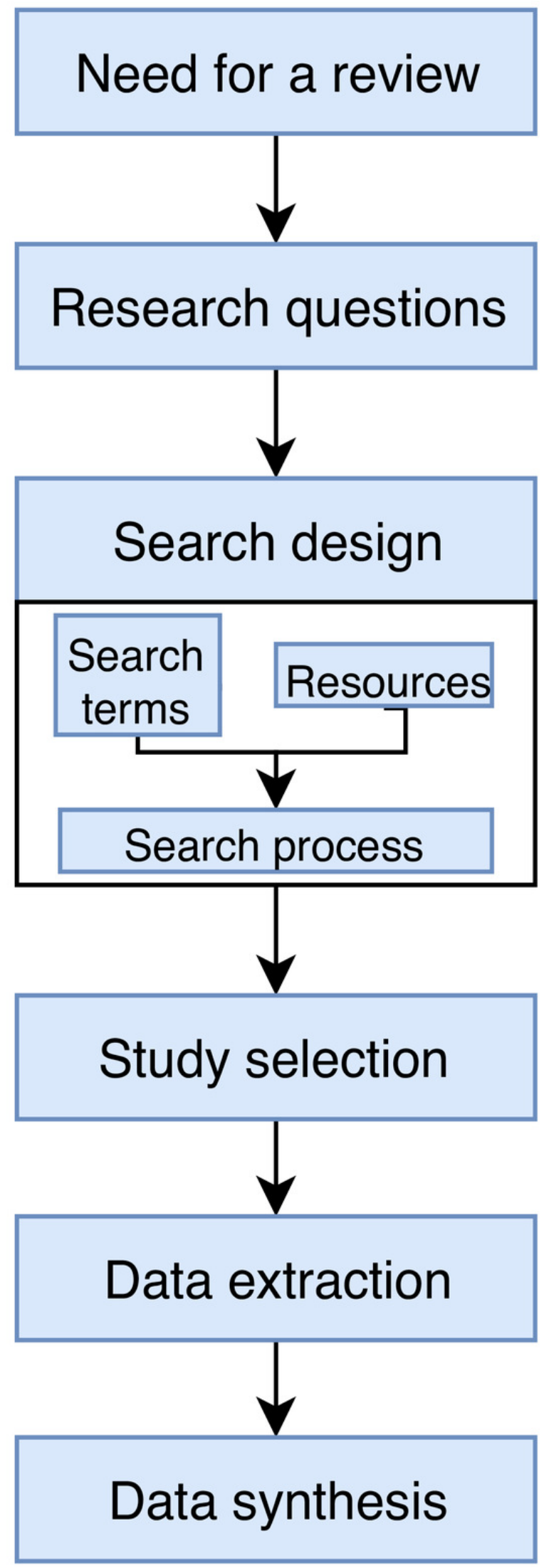


Figure 3

Classification of TEs following Rexdb and GyDB nomenclatures. Adapted from: Schietgat et al. (2018). 


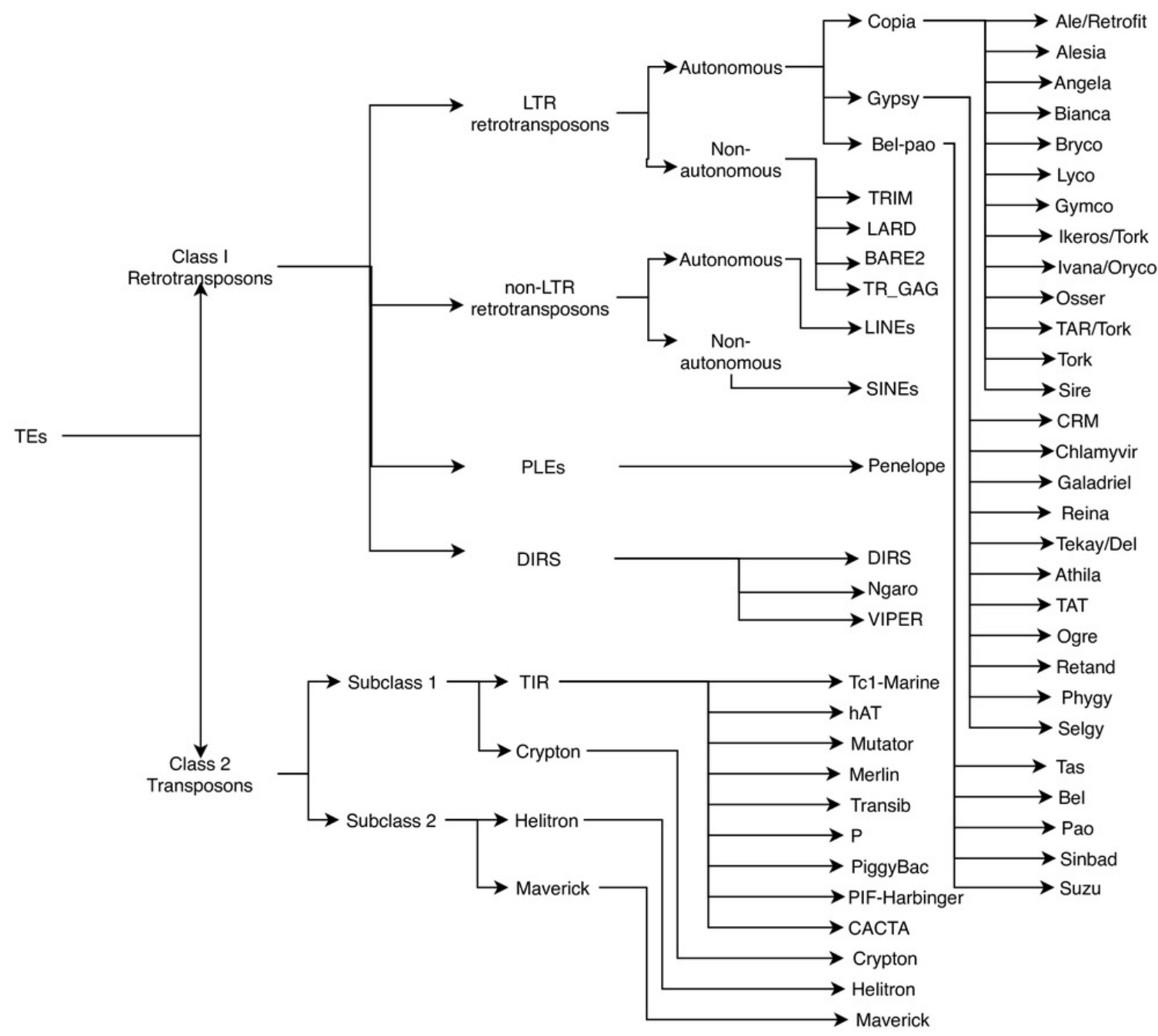

Levels:

Classes Subclasses Orders

Autonomy

Superfamilies

Lineages 
Figure 4

Number of relevant publications found per year.

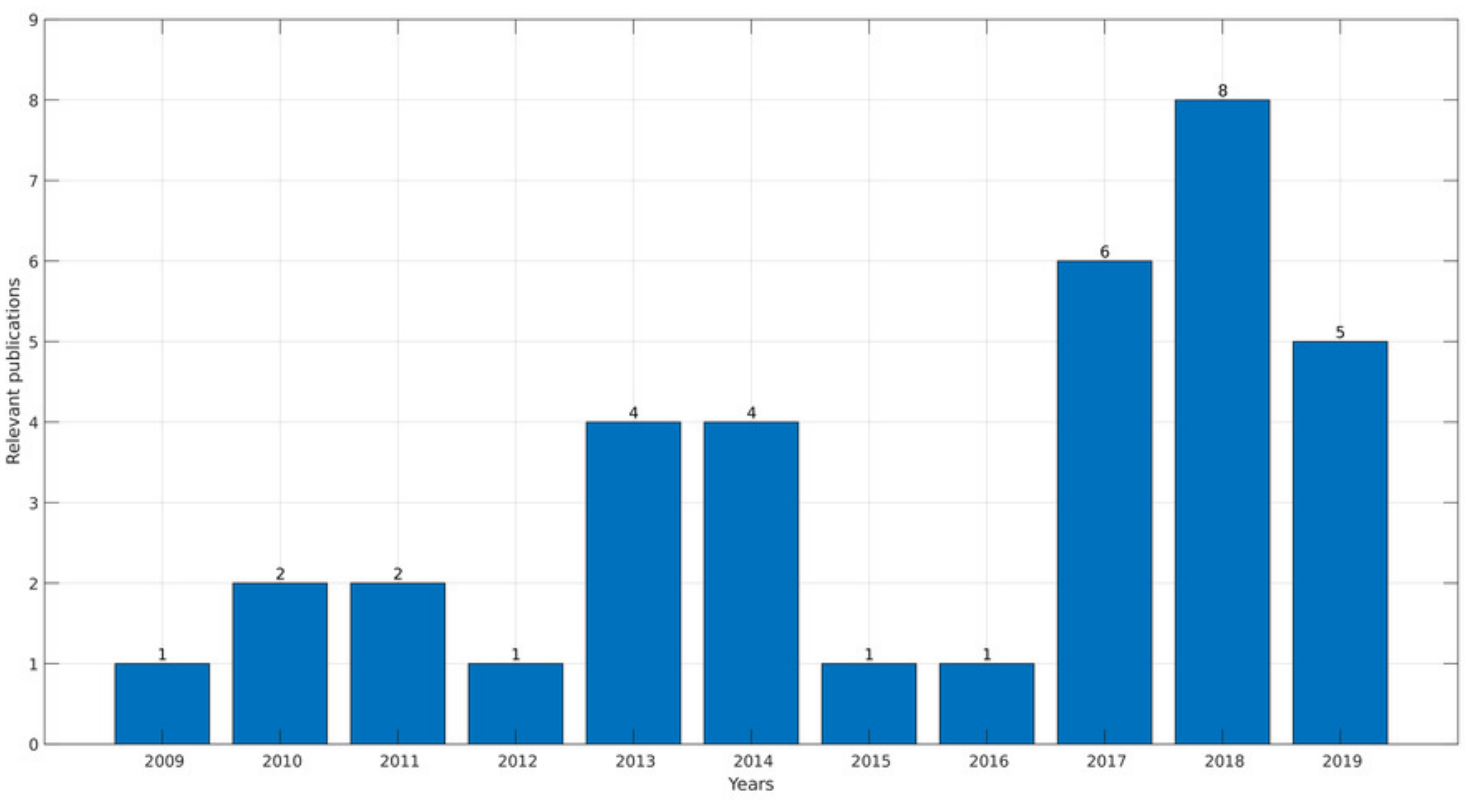




\section{Figure 5}

Source of selected publications. A) percentage of publications in each source. B) distribution of publications in journals.
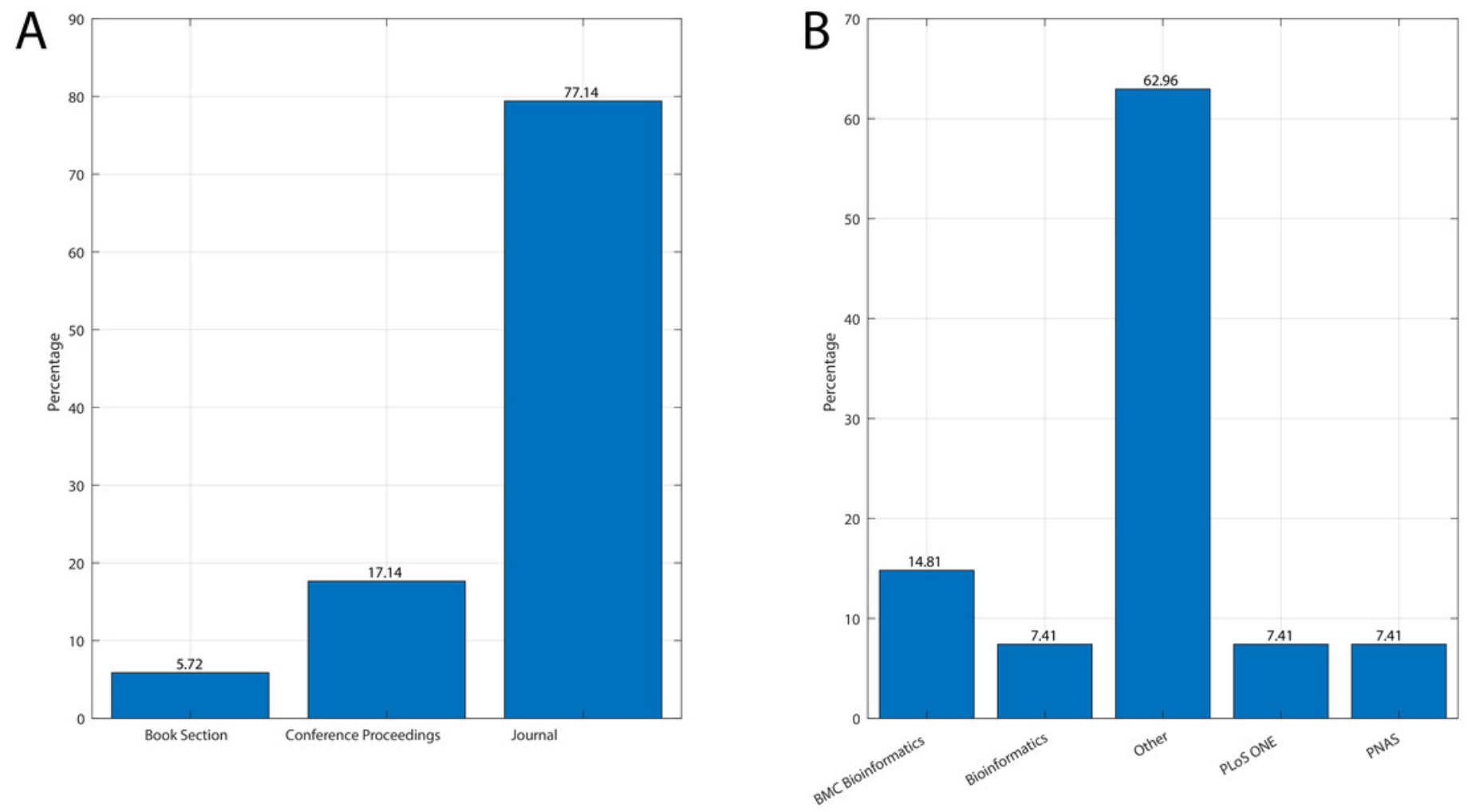


\section{Figure 6}

Source of selected publications. A) Proportion of publications using supervised and unsupervised learning. B) Supervised learning algorithms found in publications.

Abbreviations: Random Forest (RF), Decision Trees (DT), Bayesian Networks (BN), Neural networks (NN), Hidden Markov Model (HMM), Support Vector Machine (SVM), Naïve Bayes (NB), Logistic Regression (LR), K-Nearest Neighbors (KNN), and Multi-Layer Perceptron (MLP).
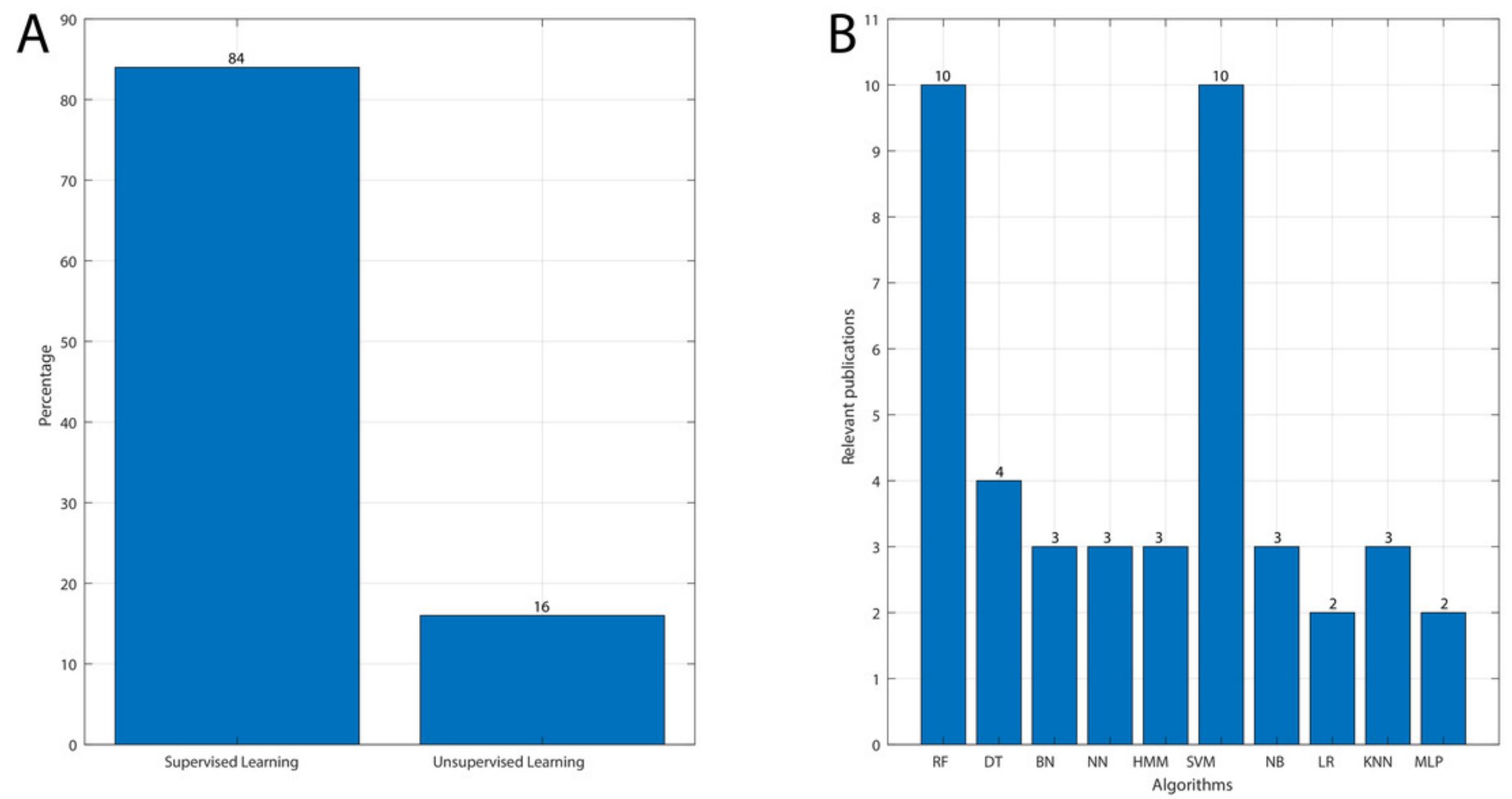
Figure 7

Overall workflow in supervised learning ML tasks applied to TEs.

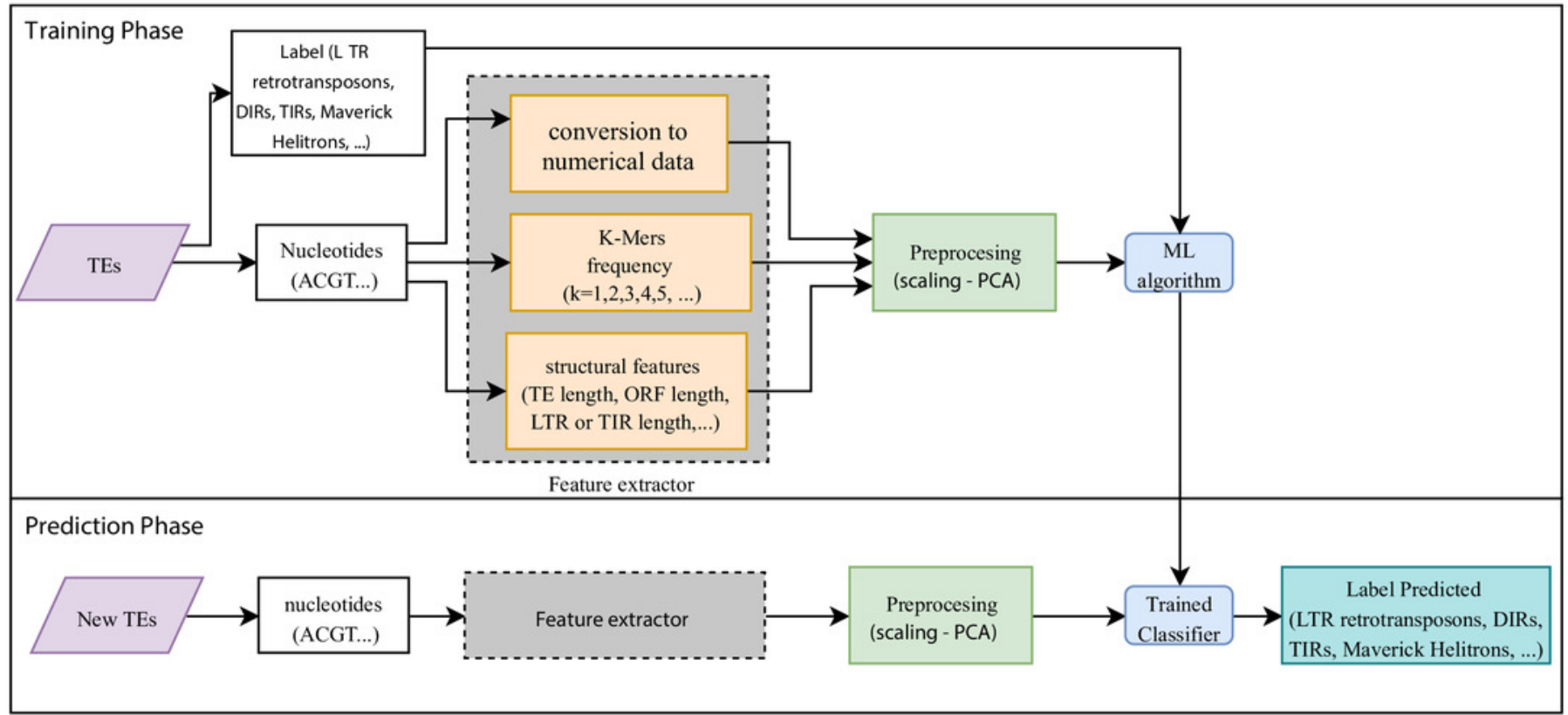


Figure 8

Overall FNN architecture used by Nakano et al. to classify TEs. Based on (Nakano et al., 2018b).

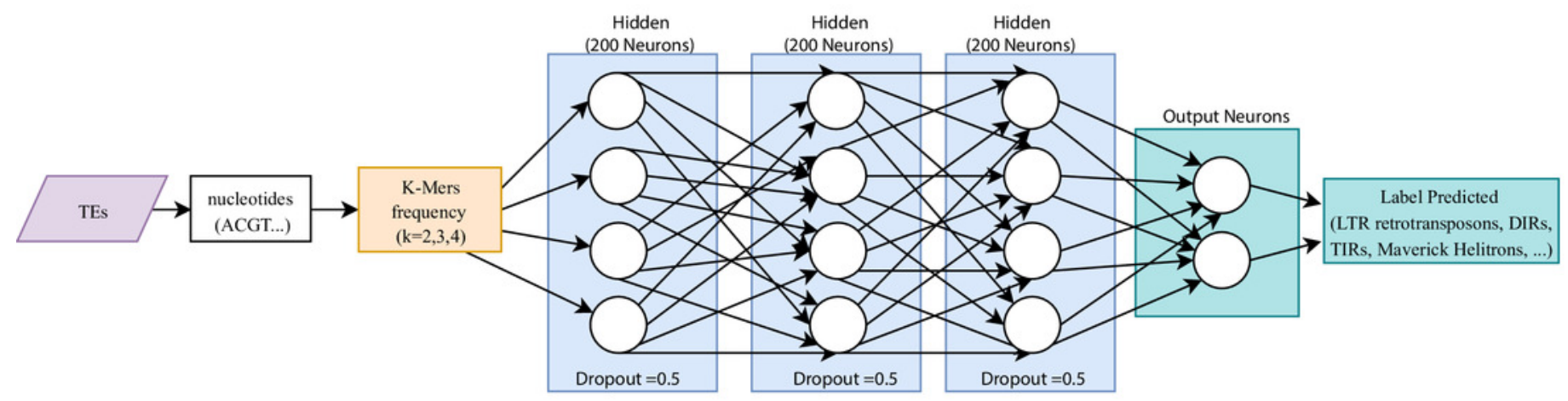


Figure 9

Overall CNN architecture used by da Cruz et al. to classify TEs. Based on (da Cruz et al., 2019).

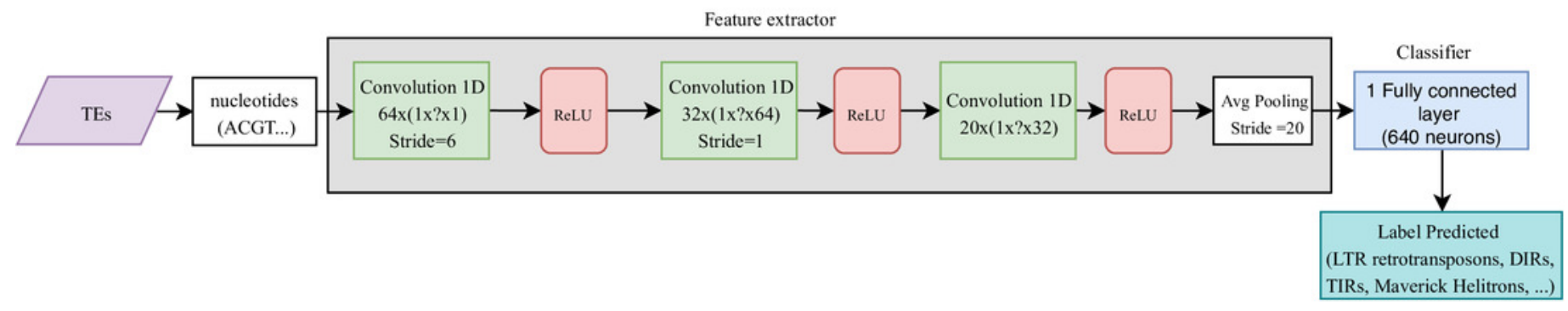


Figure 10

Equations for hierarchical metrics. $Z_{i}$ and $C_{i}$ correspond, respectively, to the set of true and predicted classes for an instance $i$.

A) Hierarchical precision, B) hierarchical recall and C) hierarchical F1-score. 

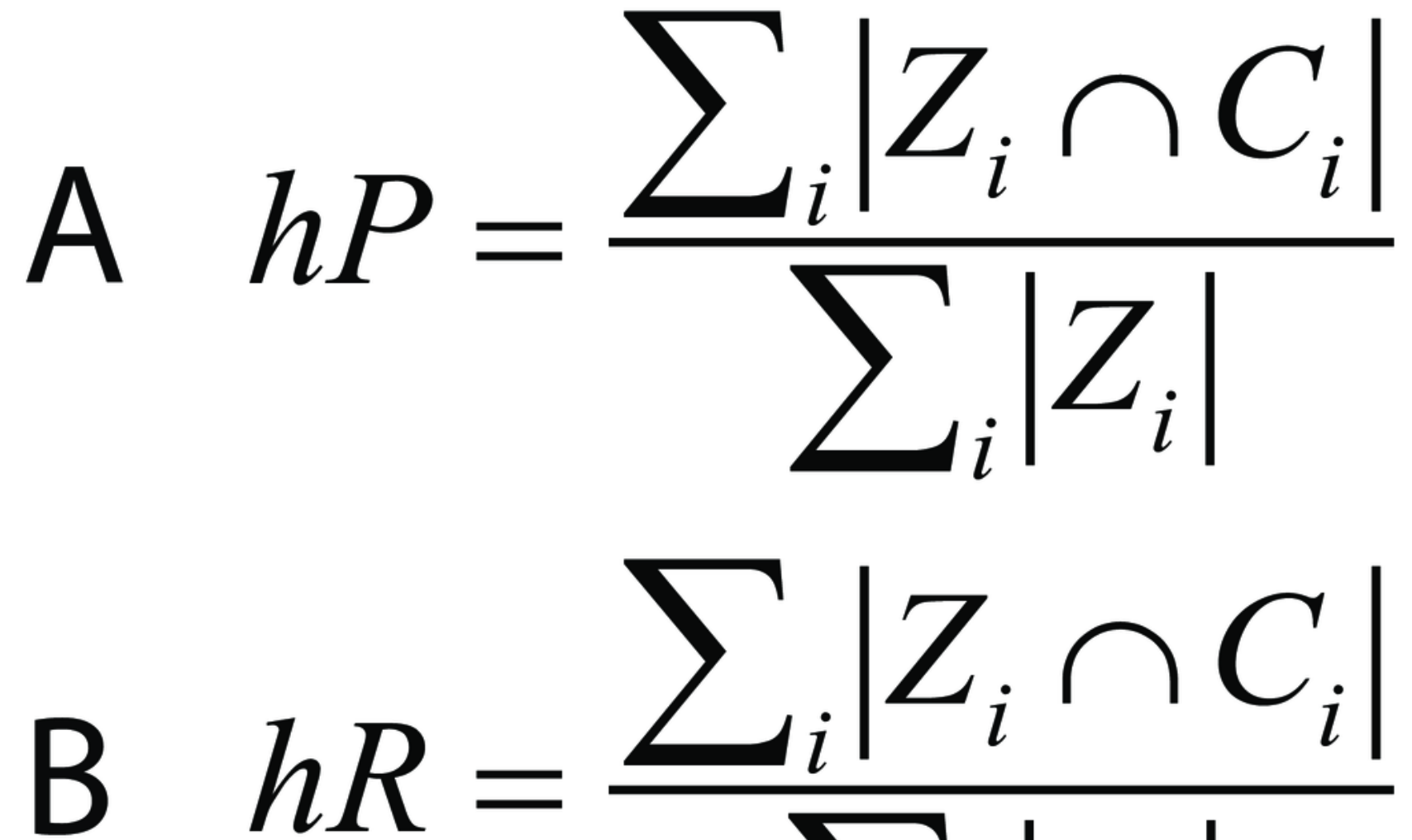

$h R=$
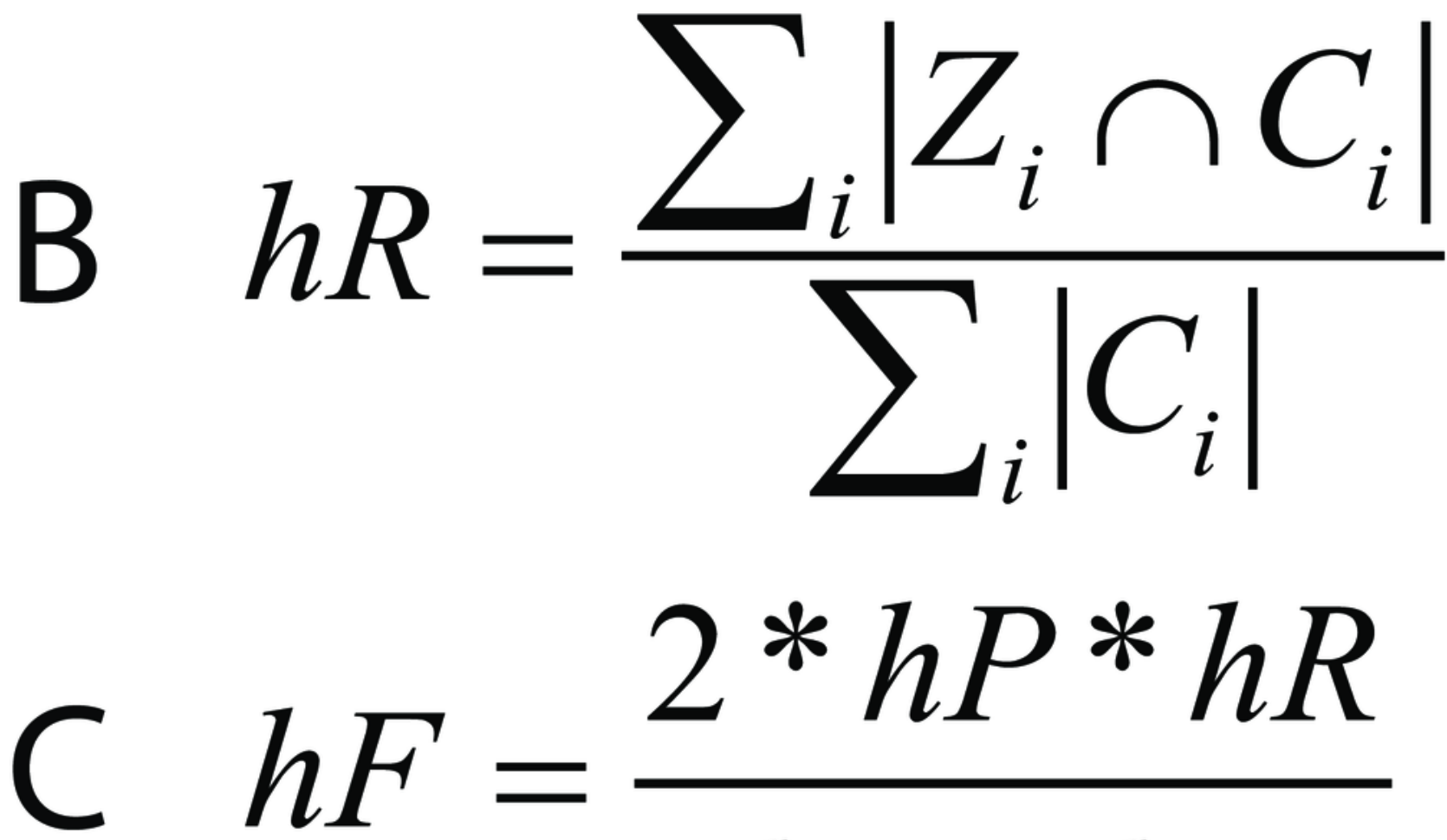

$h F=$

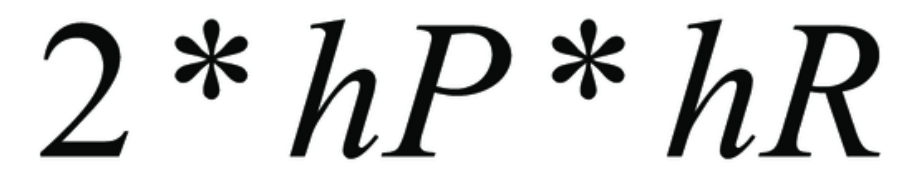

$h P+h R$ 
Table $\mathbf{1}$ (on next page)

Literature resources used in this review. 


\begin{tabular}{ll}
\hline \hline Database & Link \\
\hline Scopus & https://www.scopus.com \\
\hline Science Direct & https://www.sciencedirect.com/ \\
\hline Web of Science & $\begin{array}{l}\text { https://clarivate.com/products/web-of- } \\
\text { science/ }\end{array}$ \\
\hline SpringerLink & https://link.springer.com/ \\
\hline PubMed & https://www.ncbi.nlm.nih.gov/pubmed/ \\
\hline Nature & https://www.nature.com/ \\
\hline
\end{tabular}

1 


\section{Table 2 (on next page)}

Selected publications and their contribution to each research question. 


\begin{tabular}{|c|c|c|c|c|c|c|c|c|c|c|c|c|c|}
\hline $\begin{array}{l}\text { Publication } \\
\text { identifier }\end{array}$ & Year & Q1 & Q2 & Q3 & Q4 & Reference & $\begin{array}{l}\text { Publication } \\
\text { identifier }\end{array}$ & Year & Q1 & Q2 & Q3 & Q4 & Reference \\
\hline $\mathrm{P} 1$ & 2017 & $\mathrm{X}$ & $\mathrm{X}$ & $\mathrm{X}$ & $\mathrm{X}$ & (Yu, Yu \& Pan, 2017) & P19 & 2013 & $\mathrm{X}$ & $\mathrm{X}$ & $\mathrm{X}$ & & (Loureiro et al., 2013b) \\
\hline $\mathrm{P} 2$ & 2018 & $x$ & $x$ & $x$ & & $\begin{array}{l}\text { (Schietgat et al., } \\
2018 \text { ) }\end{array}$ & P20 & 2014 & & $x$ & $\mathrm{X}$ & & $\begin{array}{l}\text { (Ma, Zhang \& Wang, } \\
\text { 2014) }\end{array}$ \\
\hline P3 & 2017 & $x$ & $x$ & $\mathrm{X}$ & & $\begin{array}{l}\text { (Arango-López et al., } \\
\text { 2017) }\end{array}$ & $\mathrm{P} 21$ & 2010 & $x$ & $x$ & & & $\begin{array}{l}\text { (Dashti \& Masoudi- } \\
\text { Nejad, 2010) }\end{array}$ \\
\hline P4 & 2013 & $X$ & $X$ & $X$ & & $\begin{array}{l}\text { (Loureiro et al., } \\
\text { 2013a) }\end{array}$ & $\mathrm{P} 22$ & 2010 & & $X$ & $X$ & & $\begin{array}{l}\text { (Ding, Zhou \& Guan, } \\
\text { 2010) }\end{array}$ \\
\hline P5 & 2011 & $x$ & $X$ & $X$ & & (Tsafnat et al., 2011) & P23 & 2019 & & & & $\mathrm{X}$ & $\begin{array}{l}\text { (Jaiswal \& } \\
\text { Krishnamachari, 2019) }\end{array}$ \\
\hline P6 & 2018 & $x$ & $x$ & $X$ & & (Zhang et al., 2018) & P24 & 2015 & $x$ & $x$ & $x$ & $x$ & (Girgis, 2015) \\
\hline P7 & 2019 & $x$ & $x$ & & $x$ & (Eraslan et al., 2019) & P25 & 2018 & & $x$ & $\mathrm{X}$ & $x$ & (Nakano et al., 2018a) \\
\hline P8 & 2018 & $x$ & $x$ & $x$ & & (Douville et al., 2018) & P26 & 2018 & & $x$ & $\mathrm{X}$ & $x$ & $\begin{array}{l}\text { (Zamith Santos et al., } \\
2018 \text { ) }\end{array}$ \\
\hline P9 & 2018 & & $x$ & $\mathrm{X}$ & & (Chen et al., 2018) & $\mathrm{P} 27$ & 2009 & & $x$ & & & (Abrusan et al., 2009) \\
\hline P10 & 2012 & $x$ & $x$ & $x$ & $x$ & $\begin{array}{l}\text { (Ashlock \& Datta, } \\
\text { 2012) }\end{array}$ & P28 & 2019 & $x$ & $X$ & & & $\begin{array}{l}\text { (Su, Gu \& Peterson, } \\
2019)\end{array}$ \\
\hline P11 & 2017 & $x$ & $x$ & $x$ & & (Smith et al., 2017) & P29 & 2017 & $x$ & $\mathrm{X}$ & $x$ & $x$ & (Nakano et al., 2017) \\
\hline P12 & 2014 & $x$ & $\mathrm{x}$ & $x$ & $x$ & $\begin{array}{l}\text { (Kamath, De Jong \& } \\
\text { Shehu, 2014) }\end{array}$ & P30 & 2014 & & $X$ & $x$ & $x$ & (Brayet et al., 2014) \\
\hline P13 & 2016 & $\mathrm{X}$ & $X$ & $\mathrm{X}$ & & (Kim et al., 2016) & P31 & 2013 & & $\mathrm{X}$ & & & (Zamani et al., 2013) \\
\hline P14 & 2018 & $x$ & $x$ & $\mathrm{X}$ & & (Segal et al., 2018) & P32 & 2019 & & $x$ & & & (Hubbard et al., 2019) \\
\hline P15 & 2011 & $x$ & $x$ & $\mathrm{X}$ & & $\begin{array}{l}\text { (Rawal \& } \\
\text { Ramaswamy, 2011) }\end{array}$ & P33 & 2014 & & $x$ & $x$ & & (Ryvkin et al., 2014) \\
\hline P16 & 2017 & $x$ & $x$ & $\mathrm{X}$ & & (Tang et al., 2017) & P34 & 2013 & $x$ & $\mathrm{X}$ & $x$ & $x$ & (Zhang et al., 2013) \\
\hline P17 & 2017 & $x$ & $x$ & $\mathrm{X}$ & & (Ventola et al., 2017) & P35 & 2019 & & $x$ & $x$ & & (da Cruz et al., 2019) \\
\hline P18 & 2018 & & $x$ & $x$ & $x$ & (Nakano et al., 2018b) & & & & & & & \\
\hline
\end{tabular}




\section{Table 3 (on next page)}

Machine learning algorithms used in publications selected in this study.

Abbreviations: Random Forest (RF), Decision Trees (DT), Bayesian Networks (BN), Neural networks (NN), Hidden Markov Model (HMM), Support Vector Machine (SVM), Naïve Bayes (NB), Logistic Regression (LR), K-Nearest Neighbors (KNN), Self-Organizing Map (SOM), Principal Component Analysis (PCA), Multi-Layer Perceptron (MLP), first-order random forests (FORF). The full version of this table can be consulted in Table S1. 


\begin{tabular}{|c|c|c|c|c|c|}
\hline Publication & Data Source & Task & $\begin{array}{l}\mathrm{ML} \\
\text { algorithm }\end{array}$ & $\begin{array}{l}\text { Learning } \\
\text { method }\end{array}$ & Reference \\
\hline P2 & $\begin{array}{l}\text { Numerical and } \\
\text { categorical } \\
\text { features based } \\
\text { on coding } \\
\text { regions }\end{array}$ & $\begin{array}{l}\text { Detect LTR Retrotransposons } \\
\text { at the super-family level }\end{array}$ & $\mathrm{RF}$ & Supervised & $\begin{array}{l}\text { (Schietgat } \\
\text { et al., } \\
2018 \text { ) }\end{array}$ \\
\hline P3 & $\begin{array}{l}\text { Numerical and } \\
\text { categorical } \\
\text { features }\end{array}$ & $\begin{array}{l}\text { Classify LTR } \\
\text { Retrotransposons at the } \\
\text { lineage level }\end{array}$ & $\begin{array}{l}\text { DT, BN and } \\
\text { lazy } \\
\text { algorithms }\end{array}$ & Supervised & $\begin{array}{l}\text { (Arango- } \\
\text { López et } \\
\text { al., 2017) }\end{array}$ \\
\hline P4 & $\begin{array}{l}\text { Numerical and } \\
\text { categorical } \\
\text { features }\end{array}$ & $\begin{array}{l}\text { Improve the detection and } \\
\text { classification of TEs }\end{array}$ & $\begin{array}{l}\text { NN, BN, RF, } \\
\text { DT }\end{array}$ & Supervised & $\begin{array}{l}\text { (Castellan } \\
\text { os-Garzón } \\
\text { \& Díaz, } \\
\text { 2013) }\end{array}$ \\
\hline P5 & $\begin{array}{l}\text { Numerical } \\
\text { features based } \\
\text { on structure }\end{array}$ & $\begin{array}{l}\text { Detect boundary sequences of } \\
\text { mobile elements }\end{array}$ & HMM, SVM & $\begin{array}{l}\text { Unsupervised } \\
\text { and } \\
\text { Supervised }\end{array}$ & $\begin{array}{l}\text { (Tsafnat } \\
\text { et al., } \\
\text { 2011) }\end{array}$ \\
\hline P6 & $\begin{array}{l}85 \text { numerical } \\
\text { features in four } \\
\text { categories } \\
\text { (genomic, } \\
\text { epigenetic, } \\
\text { expression, } \\
\text { network) } \\
\end{array}$ & $\begin{array}{l}\text { Detection of cancer-related } \\
\text { long non-coding RNA }\end{array}$ & $\begin{array}{l}\text { RF, NB, } \\
\text { SVM, LR } \\
\text { and KNN }\end{array}$ & Supervised & $\begin{array}{l}\text { (Zhang et } \\
\text { al., 2018) }\end{array}$ \\
\hline P8 & $\begin{array}{l}\text { Z-score } \\
\text { features, } \\
\text { representing } \\
\text { chromosome } \\
\text { arm gains and } \\
\text { losses. }\end{array}$ & Detection of aneuploidy & SVM & Supervised & $\begin{array}{l}\text { (Douville } \\
\text { et al., } \\
2018 \text { ) }\end{array}$ \\
\hline P10 & $\begin{array}{l}\text { K-mer } \\
\text { frequencies } \\
\text { and } \\
\text { frequencies of } \\
\text { certain patterns } \\
\end{array}$ & $\begin{array}{l}\text { Distinguishing Endogenous } \\
\text { Retroviral LTRs from SINEs }\end{array}$ & $\mathrm{RF}$ & Supervised & $\begin{array}{l}\text { (Ashlock } \\
\& \text { Datta, } \\
\text { 2012) }\end{array}$ \\
\hline P11 & $\begin{array}{l}\text { Dinucleotide } \\
\text { frequencies }\end{array}$ & $\begin{array}{l}\text { Identification and clustering of } \\
\text { RNA structure motifs }\end{array}$ & $\begin{array}{l}\text { Density- } \\
\text { based } \\
\text { clustering }\end{array}$ & Unsupervised & $\begin{array}{l}\text { (Smith et } \\
\text { al., 2017) }\end{array}$ \\
\hline P12 & $\begin{array}{l}\text { Sequences of } \\
\text { nucleotides } \\
\text { (DNA) and } \\
\text { categorical } \\
\text { features }\end{array}$ & $\begin{array}{l}\text { Automatization of the process } \\
\text { of extracting discriminatory } \\
\text { features for determining } \\
\text { functional properties of } \\
\text { biological sequences }\end{array}$ & $\begin{array}{l}\text { Evolutionary } \\
\text { Feature } \\
\text { Construction } \\
\text { and } \\
\text { Evolutionary } \\
\text { Feature } \\
\text { Selection }\end{array}$ & Unsupervised & $\begin{array}{l}\text { (Kamath, } \\
\text { De Jong \& } \\
\text { Shehu, } \\
\text { 2014) }\end{array}$ \\
\hline P14 & $\begin{array}{l}\text { Numerical } \\
\text { features }\end{array}$ & Analysis of mutants & $\mathrm{RF}$ & Supervised & $\begin{array}{l}\text { (Segal et } \\
\text { al., 2018) }\end{array}$ \\
\hline P15 & Insertion sites & $\begin{array}{l}\text { Identification of potential } \\
\text { insertion sites of mobile } \\
\text { elements }\end{array}$ & SVM & Supervised & $\begin{array}{l}\text { (Rawal \& } \\
\text { Ramaswa } \\
\text { my, 2011) }\end{array}$ \\
\hline P16 & $\begin{array}{l}\text { Numerical } \\
\text { features }\end{array}$ & $\begin{array}{l}\text { Identification of somatic LINE- } \\
1 \text { insertions }\end{array}$ & LR & Supervised & $\begin{array}{l}\text { (Tang et } \\
\text { al., 2017) }\end{array}$ \\
\hline
\end{tabular}




\begin{tabular}{|c|c|c|c|c|c|}
\hline P17 & $\begin{array}{l}\text { Numerical } \\
\text { features, ARN } \\
\text { mononucleotid } \\
\text { es, } \\
\text { dinucleotides } \\
\text { and } \\
\text { trinucleotides } \\
\text { frequencies, } \\
\text { Fickett score }\end{array}$ & $\begin{array}{l}\text { Identification of most } \\
\text { informative features of long } \\
\text { non-coding transcripts }\end{array}$ & $\begin{array}{l}11 \text { different } \\
\text { feature } \\
\text { selection } \\
\text { approaches, } \\
\text { SVM, RF, } \\
\text { and NB }\end{array}$ & Supervised & $\begin{array}{l}\text { (Ventola } \\
\text { et al., } \\
2017 \text { ) }\end{array}$ \\
\hline P19 & $\begin{array}{l}\text { Numerical and } \\
\text { categorical } \\
\text { features }\end{array}$ & $\begin{array}{l}\text { Improve the detection and } \\
\text { classification of TEs }\end{array}$ & $\begin{array}{l}\text { NN, BN, RF, } \\
\text { DT }\end{array}$ & Supervised & $\begin{array}{l}\text { (Loureiro } \\
\text { et al., } \\
2013 b \text { ) }\end{array}$ \\
\hline P21 & $\begin{array}{l}\text { K-mer } \\
\text { frequencies }\end{array}$ & Classify repetitive sequences & SVM & Supervised & $\begin{array}{l}\text { (Hesam \& } \\
\text { Ali, 2010) }\end{array}$ \\
\hline P22 & $\begin{array}{l}\text { Numerical } \\
\text { features }\end{array}$ & $\begin{array}{l}\text { Prediction of microRNA } \\
\text { precursors }\end{array}$ & SVM & Supervised & $\begin{array}{l}\text { (Ding, } \\
\text { Zhou \& } \\
\text { Guan, } \\
\text { 2010) }\end{array}$ \\
\hline P24 & $\begin{array}{l}\text { Sequences of } \\
\text { nucleotides } \\
\text { (DNA) }\end{array}$ & Detecting repeats de novo & HMM & Supervised & $\begin{array}{l}\text { (Girgis, } \\
2015)\end{array}$ \\
\hline P26 & $\begin{array}{l}\text { K-mer } \\
\text { frequencies }\end{array}$ & Classify TEs using hierarchical & $\begin{array}{l}\text { DT, RF, NB, } \\
\text { KNN, MLP, } \\
\text { SVM }\end{array}$ & Supervised & $\begin{array}{l}\text { (Zamith } \\
\text { Santos et } \\
\text { al., 2018) }\end{array}$ \\
\hline P27 & $\begin{array}{l}\text { K-mer } \\
\text { frequencies }\end{array}$ & Classify TEs & SVM & Supervised & $\begin{array}{l}\text { (Abrusan } \\
\text { et al., } \\
2009 \text { ) }\end{array}$ \\
\hline P28 & $\begin{array}{l}\text { Numerical } \\
\text { features based } \\
\text { on structure }\end{array}$ & $\begin{array}{l}\text { Identify sequence motifs } \\
\text { conserved in each of the five } \\
\text { major TIR superfamilies. }\end{array}$ & $\begin{array}{l}\mathrm{NN}, \mathrm{KNN}, \\
\mathrm{RF} \text {, and } \\
\text { Adaboost }\end{array}$ & Supervised & $\begin{array}{l}\text { (Su, Gu \& } \\
\text { Peterson, } \\
\text { 2019) }\end{array}$ \\
\hline P30 & $\begin{array}{l}\text { Numerical } \\
\text { features and k- } \\
\text { mer } \\
\text { frequencies }\end{array}$ & piRNA prediction & SVM & Supervised & $\begin{array}{l}\text { (Brayet et } \\
\text { al., 2014) }\end{array}$ \\
\hline P31 & $\begin{array}{l}\text { Aligned } \\
\text { genomes and } \\
\text { binary } \\
\text { representation } \\
\text { ( } 1 \text { for } \\
\text { mismatches } \\
\text { and } 0 \text { for } \\
\text { matches) }\end{array}$ & $\begin{array}{l}\text { Recognition of local } \\
\text { relationship patterns }\end{array}$ & HMM, SOM & Unsupervised & $\begin{array}{l}\text { (Zamani } \\
\text { et al., } \\
\text { 2013) }\end{array}$ \\
\hline P32 & $\begin{array}{l}\text { Numerical } \\
\text { features }\end{array}$ & $\begin{array}{l}\text { Compare multiple transposon } \\
\text { insertion sequencing studies }\end{array}$ & PCA & Unsupervised & $\begin{array}{l}\text { (Hubbard } \\
\text { et al., } \\
2019 \text { ) }\end{array}$ \\
\hline P33 & $\begin{array}{l}\text { Numerical and } \\
\text { categorical } \\
\text { features, } \\
\text { nucleotide } \\
\text { frequencies }\end{array}$ & $\begin{array}{l}\text { Classify the precursors of } \\
\text { small non-coding RNAs }\end{array}$ & RF & Supervised & $\begin{array}{l}\text { (Ryvkin et } \\
\text { al., 2014) }\end{array}$ \\
\hline P34 & $\begin{array}{l}\text { Normalized } \\
\text { numerical and } \\
\text { categorical } \\
\text { features }\end{array}$ & $\begin{array}{l}\text { Prediction of transcriptional } \\
\text { effects by intronic endogenous } \\
\text { retroviruses }\end{array}$ & MLP NN & Supervised & $\begin{array}{l}\text { (Zhang et } \\
\text { al., 2013) }\end{array}$ \\
\hline
\end{tabular}

1 
Table 4 (on next page)

DL architectures used in genomic data reviewed in (Eraslan et al., 2019). Architecture details used in each work can be consulted in Table S2. 


\begin{tabular}{|c|c|c|c|c|c|}
\hline Dataset Features & Task & DNN type & $\begin{array}{l}\text { Framework } \\
\text { or } \\
\text { language }\end{array}$ & Year & Reference \\
\hline $\begin{array}{l}\text { Presence of binding } \\
\text { motifs of splice factors } \\
\text { or sequence } \\
\text { conservation }\end{array}$ & $\begin{array}{l}\text { Predict the percentage } \\
\text { of spliced exons }\end{array}$ & $\begin{array}{l}\text { Fully } \\
\text { connected NN }\end{array}$ & $\begin{array}{l}\text { TensorFlo } \\
\mathrm{w}\end{array}$ & 2017 & $\begin{array}{l}\text { (Jha, } \\
\text { Gazzara \& } \\
\text { Barash, } \\
2017)\end{array}$ \\
\hline $\begin{array}{l}\text { Numerical features, } \mathrm{k}- \\
\text { mer frequencies }(\mathrm{k}= \\
1,2,3,4)\end{array}$ & $\begin{array}{l}\text { Prioritize potential } \\
\text { disease-causing } \\
\text { genetic variants }\end{array}$ & $\begin{array}{l}\text { Fully } \\
\text { connected NN }\end{array}$ & Matlab & 2016 & $\begin{array}{l}\text { (Liu et al., } \\
2016)\end{array}$ \\
\hline $\begin{array}{l}\text { Chromatin marks, } \\
\text { gene expression and } \\
\text { evolutionary } \\
\text { conservation }\end{array}$ & $\begin{array}{l}\text { Predict cis-regulatory } \\
\text { elements }\end{array}$ & $\begin{array}{l}\text { Fully } \\
\text { connected NN }\end{array}$ & Python & 2018 & $\begin{array}{l}\text { (Li, Shi \& } \\
\text { Wasserm } \\
\text { an, 2018) }\end{array}$ \\
\hline $\begin{array}{l}\text { Microarray and } \\
\text { sequencing data }\end{array}$ & $\begin{array}{l}\text { Predict binarized } \\
\text { in vitro and } \\
\text { in vivo binding } \\
\text { affinities }\end{array}$ & $\begin{array}{l}\text { Convolutional } \\
\text { NN }\end{array}$ & $\begin{array}{l}\text { Python + } \\
\text { CUDA }\end{array}$ & 2015 & $\begin{array}{l}\text { (Alipanahi } \\
\text { et al., } \\
2015 \text { ) }\end{array}$ \\
\hline A 1,000 bp sequence & $\begin{array}{l}\text { Predict the presence } \\
\text { or absence of } 919 \\
\text { chromatin features }\end{array}$ & $\begin{array}{l}\text { Convolutional } \\
\text { NN }\end{array}$ & LUA & 2015 & $\begin{array}{l}\text { (Zhou \& } \\
\text { Troyanska } \\
\text { ya, 2015) }\end{array}$ \\
\hline $\begin{array}{l}\text { A } 600 \mathrm{bp} \\
\text { sequence (one-hot } \\
\text { matrix) }\end{array}$ & $\begin{array}{l}\text { Predict } 164 \text { binarized } \\
\text { DNA accessibility } \\
\text { features }\end{array}$ & $\begin{array}{l}\text { Convolutional } \\
\text { NN }\end{array}$ & Torch7 & 2016 & $\begin{array}{l}\text { (Kelley, } \\
\text { Snoek \& } \\
\text { Rinn, } \\
2016) \\
\end{array}$ \\
\hline $\begin{array}{l}\text { DNA sequence (one- } \\
\text { hot matrix) }\end{array}$ & $\begin{array}{l}\text { Classify transcription } \\
\text { factor binding sites }\end{array}$ & $\begin{array}{l}\text { Convolutional } \\
\text { NN }\end{array}$ & Torch7 & 2018 & $\begin{array}{l}\text { (Wang et } \\
\text { al., 2018) }\end{array}$ \\
\hline $\begin{array}{l}\text { DNA sequence (one- } \\
\text { hot matrix) }\end{array}$ & $\begin{array}{l}\text { Predict molecular } \\
\text { phenotypes such as } \\
\text { chromatin features }\end{array}$ & $\begin{array}{l}\text { Convolutional } \\
\text { NN }\end{array}$ & $\begin{array}{l}\text { TensorFlo } \\
\text { w }\end{array}$ & 2018 & $\begin{array}{l}\text { (Kelley et } \\
\text { al., 2018) }\end{array}$ \\
\hline $\begin{array}{l}\text { DNA sequence (one- } \\
\text { hot matrix) and DNAse } \\
\text { signal }\end{array}$ & $\begin{array}{l}\text { DNA } \\
\text { contact maps }\end{array}$ & $\begin{array}{l}\text { Convolutional } \\
\text { NN }\end{array}$ & Python & 2018 & $\begin{array}{l}\text { (Schreiber } \\
\text { et al., } \\
2018)\end{array}$ \\
\hline $\begin{array}{l}\text { DNA sequence (one- } \\
\text { hot matrix) and DNAse } \\
\text { signal }\end{array}$ & DNA methylation & $\begin{array}{l}\text { Convolutional } \\
\text { NN }\end{array}$ & $\begin{array}{l}\text { Theano + } \\
\text { Keras }\end{array}$ & 2017 & $\begin{array}{l}\text { (Angermu } \\
\text { eller et al., } \\
\text { 2017) }\end{array}$ \\
\hline DNA sequences & $\begin{array}{l}\text { Transform genomic } \\
\text { sequences to } \\
\text { epigenomic features }\end{array}$ & $\begin{array}{l}\text { Convolutional } \\
\text { NN }\end{array}$ & PyTorch & 2018 & $\begin{array}{l}\text { (Zhou et } \\
\text { al., 2018) }\end{array}$ \\
\hline $\begin{array}{l}\text { K-mer frequencies } \\
\text { and their positions }\end{array}$ & $\begin{array}{l}\text { Predict translation } \\
\text { efficiency }\end{array}$ & $\begin{array}{l}\text { Convolutional } \\
\text { NN }\end{array}$ & Keras & 2017 & $\begin{array}{l}\text { (Cuperus } \\
\text { et al., } \\
2017 \text { ) }\end{array}$ \\
\hline $\begin{array}{l}\text { DNA sequence (one- } \\
\text { hot matrix) and DNAse } \\
\text { signal }\end{array}$ & $\begin{array}{l}\text { Predict RNA-binding } \\
\text { proteins }\end{array}$ & $\begin{array}{l}\text { Convolutional } \\
\text { NN }\end{array}$ & $\begin{array}{l}\text { TensorFlo } \\
\text { w }\end{array}$ & 2018 & $\begin{array}{l}\text { (Budach \& } \\
\text { Marsico, } \\
\text { 2018) }\end{array}$ \\
\hline Numerical features & $\begin{array}{l}\text { Predict microRNA } \\
\text { (miRNA) targets }\end{array}$ & $\begin{array}{l}\text { Convolutional } \\
\text { NN }\end{array}$ & - & 2016 & $\begin{array}{l}\text { (Cheng et } \\
\text { al., 2015) }\end{array}$ \\
\hline Numerical features & $\begin{array}{l}\text { Aggregate the outputs } \\
\text { of CNNs for predicting } \\
\text { single-cell DNA } \\
\text { methylation state }\end{array}$ & Recurrent NN & $\begin{array}{l}\text { Theano + } \\
\text { Keras }\end{array}$ & 2017 & $\begin{array}{l}\text { (Angermu } \\
\text { eller et al., } \\
2017 \text { ) }\end{array}$ \\
\hline $\begin{array}{l}\text { RNA sequence (one- } \\
\text { hot matrix) }\end{array}$ & $\begin{array}{l}\text { Predict RNA-binding } \\
\text { proteins }\end{array}$ & Recurrent NN & Keras & 2018 & $\begin{array}{l}\text { (Pan et } \\
\text { al., 2018) }\end{array}$ \\
\hline DNA sequence (one- & Predict transcription & Recurrent NN & Theano + & 2019 & (Quang \& \\
\hline
\end{tabular}




\begin{tabular}{|c|c|c|c|c|c|}
\hline hot matrix) & $\begin{array}{l}\text { factor binding and } \\
\text { DNA accessibility }\end{array}$ & & Keras & & Xie, 2019) \\
\hline $\begin{array}{l}\text { RNA sequence } \\
\text { (weight matrices) }\end{array}$ & $\begin{array}{l}\text { Predict the occurrence } \\
\text { of precursor miRNAs } \\
\text { from the mRNA } \\
\text { sequence }\end{array}$ & Recurrent NN & $\begin{array}{l}\text { Theano + } \\
\text { Keras }\end{array}$ & 2016 & $\begin{array}{l}\text { (Park et } \\
\text { al., 2016) }\end{array}$ \\
\hline $\begin{array}{l}\text { Gene expression level } \\
\text { (binary, over or under- } \\
\text { expressed) }\end{array}$ & $\begin{array}{l}\text { Predict binarized gene } \\
\text { expression given the } \\
\text { expression of other } \\
\text { genes }\end{array}$ & $\begin{array}{l}\text { Graph- } \\
\text { convolutional } \\
\text { NN }\end{array}$ & Torch7 & 2018 & $\begin{array}{l}\text { (Dutil et } \\
\text { al., 2018) }\end{array}$ \\
\hline $\begin{array}{l}\text { Gene expression } \\
\text { profile and protein- } \\
\text { protein interaction } \\
\text { network }\end{array}$ & $\begin{array}{l}\text { Classify cancer } \\
\text { subtypes }\end{array}$ & $\begin{array}{l}\text { Graph- } \\
\text { convolutional } \\
\text { NN }\end{array}$ & - & 2017 & $\begin{array}{l}\text { (Rhee, } \\
\text { Seo \& } \\
\text { Kim, } \\
2017)\end{array}$ \\
\hline
\end{tabular}

1 


\section{Table 5 (on next page)}

Metrics used in TEs and other similar tasks.

Adopted from (Kamath, De Jong \& Shehu, 2014; Brayet et al., 2014; Ma, Zhang \& Wang, 2014; Yu, Yu \& Pan, 2017; Smith et al., 2017; Chen et al., 2018; Schietgat et al., 2018; Segal et al., 2018). D for detection and C for classification. 


\begin{tabular}{|c|c|c|c|}
\hline Metric & Representation & Observations & $\begin{array}{c}\text { Tasks in } \\
\text { which it was } \\
\text { used }\end{array}$ \\
\hline \multirow{2}{*}{ Accuracy } & $(T P+T N)$ & \multirow{2}{*}{$\begin{array}{l}\text { Measures the } \\
\text { percentage of } \\
\text { samples that are } \\
\text { correctly } \\
\text { classified }\end{array}$} & \multirow{2}{*}{$D, C$} \\
\hline & $\overline{(T P+F P+F N+T N)}$ & & \\
\hline \multirow{2}{*}{ Precision } & $T P$ & \multirow{2}{*}{$\begin{array}{l}\text { Percentage of } \\
\text { correct } \\
\text { predictions }\end{array}$} & \multirow[b]{2}{*}{$\mathrm{D}$} \\
\hline & $\overline{(T P+F P)}$ & & \\
\hline \multirow{2}{*}{$\begin{array}{l}\text { Sensitivity } \\
\text { (recall) }\end{array}$} & $T P$ & \multirow{2}{*}{$\begin{array}{l}\text { Represents the } \\
\text { proportion of } \\
\text { positive samples } \\
\text { that are correctly } \\
\text { predicted }\end{array}$} & \multirow{2}{*}{$\mathrm{D}, \mathrm{C}$} \\
\hline & $\overline{(T P+F N)}$ & & \\
\hline \multirow[b]{2}{*}{ Specificity } & $T N$ & \multirow{2}{*}{$\begin{array}{l}\text { Represents the } \\
\text { proportion of } \\
\text { negative samples } \\
\text { that are correctly } \\
\text { predicted }\end{array}$} & \multirow{2}{*}{$\mathrm{D}$} \\
\hline & $\overline{(T N+F P)}$ & & \\
\hline \multirow{2}{*}{$\begin{array}{l}\text { Matthews } \\
\text { correlation } \\
\text { coefficient }\end{array}$} & $T P \times T N-F N \times F P$ & \multirow{2}{*}{$\begin{array}{l}\text { It can be a key } \\
\text { measurement } \\
\text { because it is a } \\
\text { balanced } \\
\text { measurement, } \\
\text { even if the sizes } \\
\text { of positive and } \\
\text { negative samples } \\
\text { have great } \\
\text { differences. }\end{array}$} & \multirow{2}{*}{$\mathrm{D}$} \\
\hline & $\sqrt{(T P+F N) \times(T N+F P) \times(T P+F P) \times(T N+F N)}$ & & \\
\hline \multirow{2}{*}{$\begin{array}{l}\text { Positive } \\
\text { predictive } \\
\text { value }\end{array}$} & $T P$ & \multirow{2}{*}{$\begin{array}{l}\text { Percentage of } \\
\text { correctly } \\
\text { classified positive } \\
\text { samples among } \\
\text { all positive- } \\
\text { classified ones }\end{array}$} & \multirow{2}{*}{$\mathrm{D}, \mathrm{C}$} \\
\hline & $\overline{(T P+F P)}$ & & \\
\hline \multirow{2}{*}{$\begin{array}{l}\text { Performance } \\
\text { coefficient }\end{array}$} & $T P$ & \multirow{2}{*}{$\begin{array}{l}\text { Ratio of correct } \\
\text { predictions } \\
\text { belonging to the } \\
\text { positive class and } \\
\text { predictions } \\
\text { belonging to the } \\
\text { false class }\end{array}$} & \multirow{2}{*}{$\mathrm{D}$} \\
\hline & $\overline{(T P+F N+F P)}$ & & \\
\hline \multirow{2}{*}{ F1 score } & $2 \times T P$ & \multirow{2}{*}{$\begin{array}{l}\text { Harmonic mean } \\
\text { of precision and } \\
\text { sensitivity }\end{array}$} & \multirow{2}{*}{$\mathrm{D}$} \\
\hline & $\overline{(2 \times T P+F P+F N)}$ & & \\
\hline $\begin{array}{l}\text { Precision- } \\
\text { recall curves }\end{array}$ & Graphics & $\begin{array}{l}\text { Plots the } \\
\text { precision of a } \\
\text { model as a } \\
\text { function of its } \\
\text { recall }\end{array}$ & $D, C$ \\
\hline $\begin{array}{l}\text { Receiver } \\
\text { Operating }\end{array}$ & Graphics & $\begin{array}{l}\text { Commonly used } \\
\text { to evaluate the }\end{array}$ & C \\
\hline
\end{tabular}




\begin{tabular}{|c|c|c|c|}
\hline $\begin{array}{l}\text { Characteristic } \\
\text { curves } \\
\text { (ROCs) }\end{array}$ & & $\begin{array}{l}\text { discriminative } \\
\text { power of the } \\
\text { classification } \\
\text { model at different } \\
\text { thresholds }\end{array}$ & \\
\hline $\begin{array}{l}\text { Area under } \\
\text { the ROC } \\
\text { curve (AUC) }\end{array}$ & Graphics & $\begin{array}{l}\text { Summary } \\
\text { measure that } \\
\text { indicates whether } \\
\text { prediction } \\
\text { performance is } \\
\text { close to random } \\
(0: 5) \text { or perfect } \\
(1: 0) \text {. Also } \\
\text { describes the } \\
\text { sensitivity } \\
\text { versus the } \\
\text { specificity of the } \\
\text { prediction }\end{array}$ & $\mathrm{D}, \mathrm{C}$ \\
\hline $\begin{array}{l}\text { Area under } \\
\text { the Precision } \\
\text { Recall Curve } \\
\text { (auPRC) }\end{array}$ & Graphics & $\begin{array}{l}\text { Measures the } \\
\text { fraction of } \\
\text { negatives } \\
\text { misclassified as } \\
\text { positives and } \\
\text { plots the } \\
\text { precision vs. } \\
\text { recall ratio }\end{array}$ & D \\
\hline $\begin{array}{l}\text { False positive } \\
\text { rate }\end{array}$ & 1 - Specificity & $\begin{array}{l}\text { Percentage of } \\
\text { predictions } \\
\text { marked as } \\
\text { belonging to the } \\
\text { positive class, but } \\
\text { that are part of } \\
\text { the negative } \\
\text { class. }\end{array}$ & $D$ \\
\hline
\end{tabular}

1 
Table 6(on next page)

Coding schemes for translating DNA characters in numerical representations. Adapted from (Yu, Yu \& Pan, 2017). 


\begin{tabular}{|c|c|c|}
\hline $\begin{array}{l}\text { Encoding } \\
\text { Schemes }\end{array}$ & Codebook & Reference \\
\hline DAX & $\left\{C^{\prime}: 0, ' T\right.$ ':1, 'A':2, ‘G':3\} & Yu et al. (2015) \\
\hline EIIP & $\begin{array}{l}\left\{C^{\prime}: 0.1340, ' T ': 0.1335, ' A ': 0.1260,\right. \\
\text { 'G':0.0806\} }\end{array}$ & Nair and Sreenadhan (2006) \\
\hline Complementary & $\left\{{ }^{\prime} C^{\prime}:-1,{ }^{\prime} T\right.$ ':-2, 'A':2, 'G':1\} & Akhtar et al. (2008) \\
\hline Enthalpy & $\begin{array}{l}\{C C ': 0.11, \text { 'TT':0.091, 'AA':0.091, } \\
\text { 'GG':0.11, 'CT':0.078, 'TA':0.06, } \\
\text { 'AG':0.078, 'CA':0.058, 'TG':0.058, } \\
\text { 'CG': 0.119, 'TC':0.056, 'AT':0.086, } \\
\text { 'GA':0.056, 'AC':0.065, 'GT':0.065, } \\
\text { 'GC':0.1111\} }\end{array}$ & Kauer and Blöcker (2003) \\
\hline Galois (4) & $\begin{array}{l}\{C C \text { '0.0, 'CT':1.0, 'CA':2.0, 'CG':3.0, } \\
\text { 'TC':4.0, 'TT':5.0, 'TA':6.0, 'TG':7.0, } \\
\text { 'AC:8.0, 'AT: } 9.0, \text { 'AA':1.0, 'AG:11.0, } \\
\text { 'GC':12.0, 'GT':13.0, 'GA':14.0, } \\
\text { 'GG':15.0\} }\end{array}$ & Rosen (2006) \\
\hline $\begin{array}{l}\text { Orthogonal (one- } \\
\text { hot) Encoding }\end{array}$ & $\begin{array}{l}\left\{A^{\prime}:[1,0,0,0], ' C ':[0,1,0,0], ' T \text { ': }\right. \\
[0,0,1,0], \text { 'G': }[0,0,0,1]\}\end{array}$ & Baldi et al. (2001) \\
\hline
\end{tabular}

1 